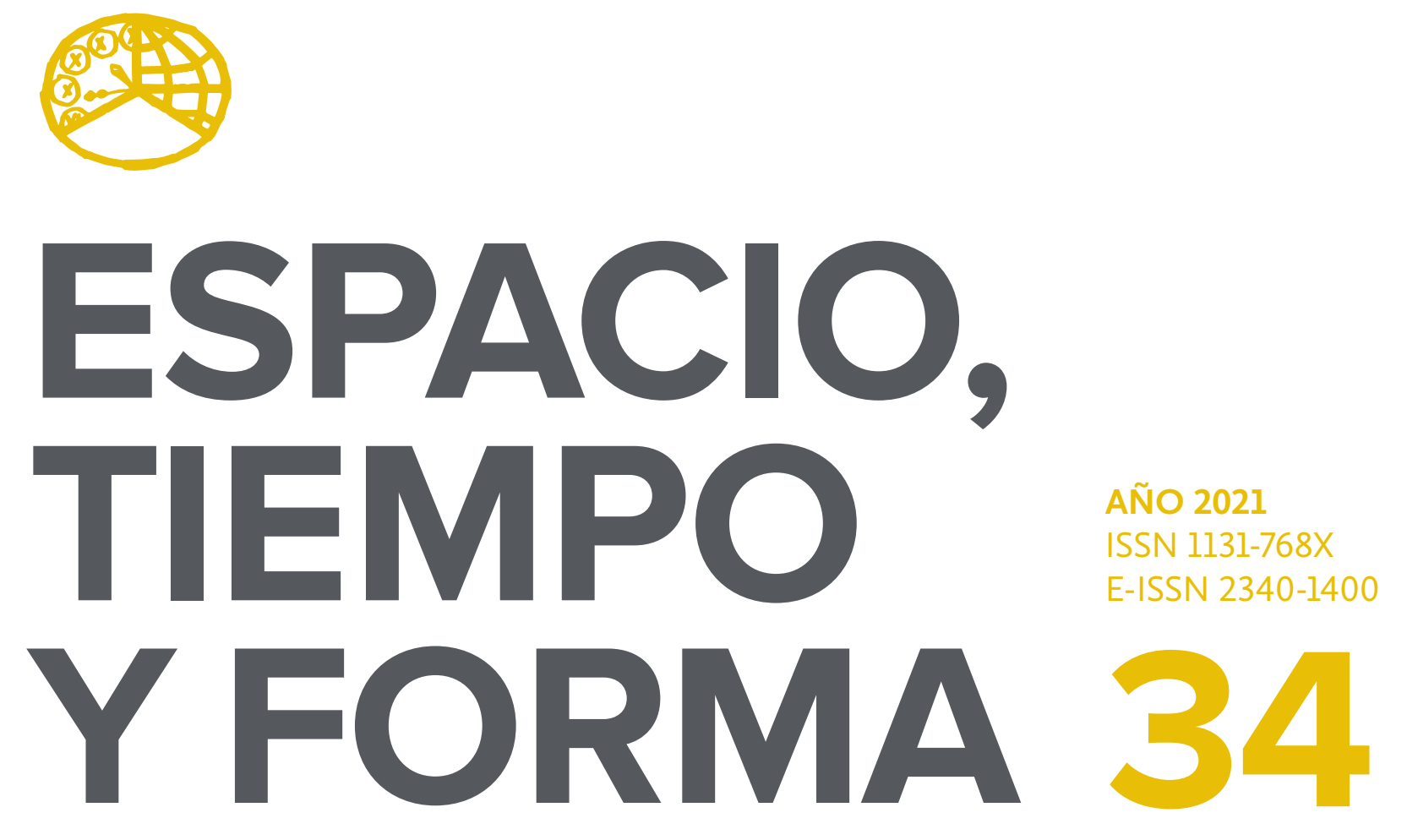

SERIE IV HISTORIA MODERNA

REVISTA DE LA FACULTAD DE GEOGRAFÍA E HISTORIA

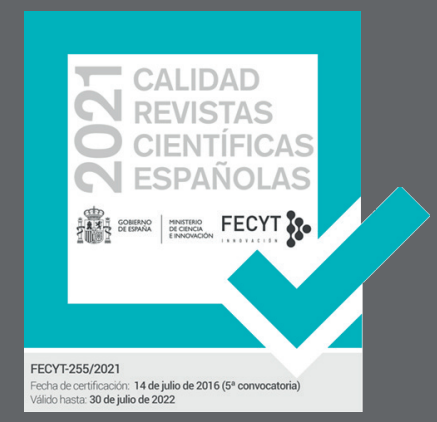




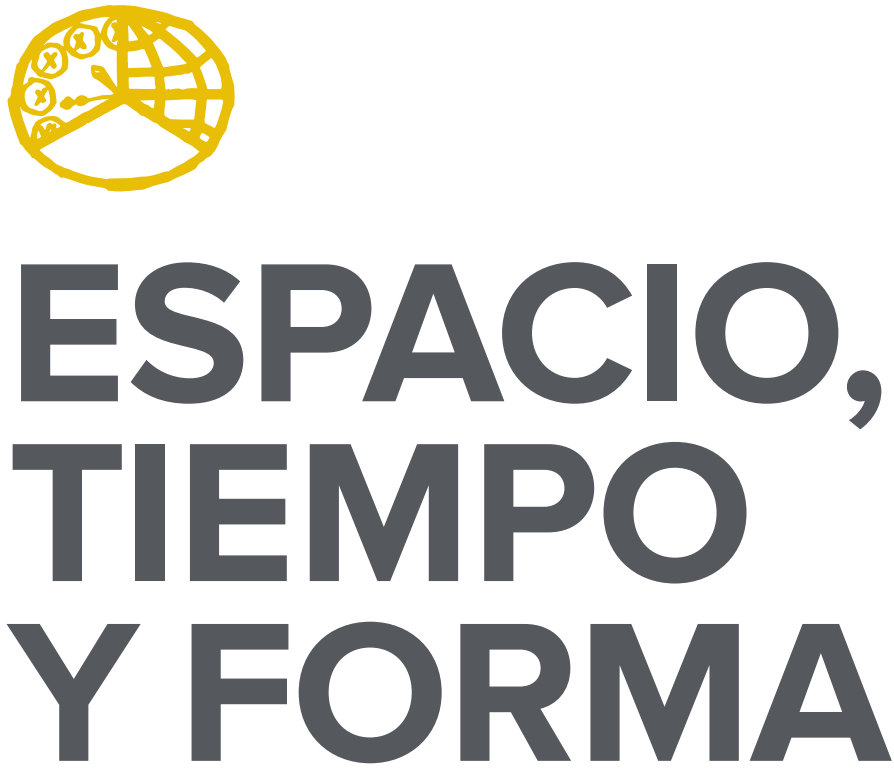

AÑO 2021

ISSN 1131-768X

E-ISSN 2340-1400

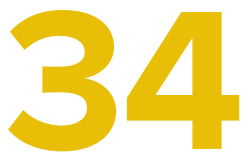

SERIE IV HISTORIA MODERNA

REVISTA DE LA FACULTAD DE GEOGRAFÍA E HISTORIA

DOI: https://doi.org/10.5944/etfiv.34.2021

\section{UกED}

UNIVERSIDAD NACIONAL DE EDUCACIÓN A DISTANCIA 
La revista Espacio, Tiempo y Forma (siglas recomendadas: ETF), de la Facultad de Geografía e Historia de la UNED, que inició su publicación el año 1988, está organizada de la siguiente forma:

$$
\begin{aligned}
& \text { SERIE I - Prehistoria y Arqueología } \\
& \text { SERIE II - Historia Antigua } \\
& \text { SERIE III - Historia Medieval } \\
& \text { SERIE IV - Historia Moderna } \\
& \text { SERIE V - Historia Contemporánea } \\
& \text { SERIE VI - Geografía } \\
& \text { SERIE VII - Historia del Arte }
\end{aligned}
$$

Excepcionalmente, algunos volúmenes del año 1988 atienden a la siguiente numeración:

$$
\begin{aligned}
& \mathrm{N} .^{\circ} 1 \text { - Historia Contemporánea } \\
& \mathrm{N}^{\circ} 2 \text { - Historia del Arte } \\
& \mathrm{N} .^{\circ} 3 \text { - Geografía } \\
& \mathrm{N} .^{\circ} 4 \text { - Historia Moderna }
\end{aligned}
$$

ETF no se solidariza necesariamente con las opiniones expresadas por los autores.

\author{
UNIVERSIDAD NACIONAL DE EDUCACIÓN A DISTANCIA \\ Madrid, 2021 \\ SERIE IV · HISTORIA MODERNA N. ${ }^{\circ} 34,2021$ \\ ISSN $1131-768 X \cdot$ E-ISSN 2340-1400 \\ DEPÓSITO LEGAL \\ M-21.037-1988 \\ URL \\ ETF IV · HISTORIA MODERNA · http://revistas.uned.es/index.php/ETFIV \\ DISEÑO Y COMPOSICIÓN \\ Carmen Chincoa Gallardo · http://www.laurisilva.net/cch \\ Impreso en España · Printed in Spain
}

(c) (7) (8) Esta obra está bajo una licencia Creative Commons Reconocimiento-NoComercial 4.0 Internacional. 


\section{TALLER DE HISTORIOGRAFÍA .}

HISTORIOGRAPHY WORKSHOP

ENSAYOS - ESSAYS 



\title{
"TAN PELIGROSAS Y FEAS CONSPIRACIONES»: LA RELACIÓN ESCRITA POR EL EMBAJADOR AUSTRIACO CHRISTOPH MIGAZZI EN 1754 SOBRE LA CAIIDA DEL MARQUÉS DE LA ENSENADA
}

\author{
"DANGEROUS AND UGLY CONSPIRACIES". \\ THE REPORT OF THE AUSTRIAN AMBASSADOR \\ CHRISTOPH MIGAZZI ON THE FALL OF THE \\ MARQUIS OF LA ENSENADA IN 1754
}

\author{
Christoph Rosenmüller ${ }^{1}$ \\ Recibido: 04/03/2021 - Aceptado: 06/05/2021 \\ DOI: https://doi.org/10.5944/etfiv.34.2021.31605
}

El ig de agosto de I754, el embajador austriaco en Madrid, el conde (Graf) Christoph Migazzi, escribió una extensa relación a María Teresa, la reina de Bohemia y Hungría y consorte imperial en Viena, Austria (reinó I740-I780). Migazzi analizó desde la perspectiva austriaca las causas de la caída del poder del marqués de la Ensenada, el primer ministro del imperio español (I743-I754) acaecida el 2I de julio de I754. Los historiadores en los últimos años han estudiado con perspicacia el colapso del mando de Ensenada y la llegada del primer ministro Ricardo Wall, incluso el rol desempeñado por los distintos embajadores. Sin embargo, la mayoría dan a Migazzi el papel de un actor de reparto, aunque el embajador influyó en la intriga palaciega en un periodo en que Austria seguía siendo una gran potencia². Migazzi incluso reclamó que él mismo había tomado las medidas adecuadas para acabar con Ensenada y su relación aporta nuevas causas. Más allá del valor testimonial de un actor que reclama su lugar al frente del escenario, su fuente es especialmente interesante, ya que Austria y España en aquel momento habían enterrado su enemistad por los territorios en Italia y Europa estaba al borde de la reversión de alianzas de I756. Por lo anterior, el

\footnotetext{
1. Middle Tennessee State University; christoph.rosenmuller@mtsu.edu

Agradezco a Simon Edlmayr de la Academia Austriaca de Ciencias (Österreichische Akademie der Wissenschaften) por su revisión detallada del texto transcrito y a Iván Alcántar su revisión precisa del texto en español.

Österreichisches Staatsarchiv, Haus-, Hof- und Staatsarchiv, Staatenabteilung, Spanien, Diplomatische Korrespondenz (1754.05-1754.12) [ÖStA, HHStA, StA, DK].

2. Investigaciones de alta calidad incluyen Gómez URdáñez, 2001. Stein \& STEIN, 2000. Kuethe \& ANDRIEN, 2014. Hay que añadir que TÉlLez Alarcía, 2008, consulta los embajadores británico, francés e italianos y reconoce la actuación de Migazzi basándose en esas fuentes.
} 
objetivo de este artículo es reproducir la relación de Migazzi en alemán, traducirla al español e introducir el trasfondo y la importancia de su creación ${ }^{3}$.

El conde Migazzi nació en I7I4 en Trento en el seno de una familia noble establecida, pero con recursos limitados. Estudió derecho canónigo y civil en el Collegium Germanicum en Roma, recibió el doctorado en 1736 y fue ordenado sacerdote en I738. Ya había alcanzado una canonjía en la catedral de Brixen (Tirol del Sur) en I733, luego obtuvo una canonjía en Trento y, en I745, se convirtió en juez del tribunal papal en Roma representando el Sacro Imperio (Auditor Rotae Nationis Germaniae). En I752, la corona también le nombró coadjutor, es decir, suplente y probable sucesor, del arzobispo de Malinas / Bruselas 4 .

En esta época en Roma, Migazzi mejoró las relaciones de Austria con la Santa Sede y aprovechó para sondear las posibilidades de un acercamiento con España sobre los territorios disputados en Italia. El acercamiento era relevante porque María Teresa había sucedido a su padre, el emperador Carlos Vl, como reina de Hungría y Bohemia en I740. Ella misma no tomó el título imperial (aunque Migazzi se dirigió a ella como emperatriz), sino que se coronó a su esposo Francisco emperador en I745. De todas maneras, la sucesión fue impugnada, y Prusia arrebató a Austria la rica provincia de Silesia en 1740-42. Después de la segunda guerra con Prusia (1744-I745), Austria todavía se negó a reconocer la cesión de Silesia y ante la posibilidad de sostener un tercer conflicto con Prusia, trató de asegurar el flanco sur mediante un tratado con España y los príncipes italianos ${ }^{5}$. El cardenal Silvio Valenti Gonzaga, secretario de Estado del Papa, escribió a Madrid para proponer un acuerdo. En I746 José de Carvajal y Lancáster, el ministro de Estado de España (I746-I754), indicó que vio la utilidad de separarse de Francia y acercarse a Austria, pero lamentó que Ensenada tenía demasiado poder en la corte para impedir esta transformación. Sin embargo, las relaciones de España con Francia se enfriaron notablemente tras el Tratado de Aquisgrán de I748, en que los intereses de Madrid fueron ignorados. Como consecuencia, en I749, Migazzi llegó a un acuerdo preliminar con el embajador español en Roma ${ }^{6}$.

De tal modo, los acuerdos entre Austria y España avanzaron aún más. En febrero de I752, María Teresa nombró a Migazzi como plenipotenciario austriaco en la península para llevar a cabo el acuerdo. Migazzi llegó a Madrid en abril y sustituyó al embajador conde Nikolaus Esterhazy, que ya había negociado un acuerdo con Carvajal, pero se quejó de su maltrecha salud y solicitó repetidamente ser relevado. Migazzi seguía las negociaciones, especialmente con los príncipes italianos y finalmente firmó el Tratado de Aranjuez el I4 de junio / i6 de agosto de I752. El tratado estipulaba la paz y el apoyo mutuo entre Austria, España, Carlos de Nápoles y Sicilia (el futuro Carlos III de España), su hermano, Felipe de Borbón, duque de

3. Christoph Migazzi a María Teresa, Madrid, 19 de agosto de 1754, ÖStA, HHStA, StA, DK, caja 85, expediente 2, ff. $29-40 \mathrm{~V}$

4. «Migazzi, Christoph Graf <En línea> por Peter HeRsCHe: Neue Deutsche Biographie 17 (1994): 486-487. Consultado el 17 de mayo de 2021. URL: https://www.deutsche-biographie.de

5. STOLLberG-RILINGER, 2017: 89-99, 117-126, 129.

6. Wolfsgruber, 1890: 43-45. Whaley, 2011: 352. Gómez Urdáñez, 2001: 42. Véase también Ozanam, 1975: $7-8$. 
Parma, Piacenza y Guastalla y el reino de Cerdeña. Por ello, algunos personajes en Viena esperaban que el tratado con el rey Fernando VI de España (I746-I759) y los príncipes Borbónicos en Italia allanara también el camino para establecer conversaciones con la Casa de Borbón en París. Migazzi confió a Carvajal esa meta, ya que el Staatskanzler (primer ministro) austriaco, el conde Anton Kaunitz, estaba llevando a Austria en esa dirección. Sin embargo, la reversión de alianzas, también conocido como el grand renversement des alliances / Diplomatic Revolution, no ocurrió hasta I756. En este esquema, Austria dejó su antigua alianza con los poderes marítimos de Gran Bretaña y Países Bajos y forjó un acuerdo con su antigua némesis Francia para contrarrestar la expansión de Prusia en la Guerra de los Siete Años (I756-63)7.

De todas maneras, Migazzi escribió dos años antes de esa gran reversión cuando Austria ya había lanzado sus tanteos, pero todavía no había avanzado lo suficiente en sus propuestas. Además, Madrid se abstuvo de mediar entre Austria y Francia. Por lo cual, Migazzi actuó con el fin de solidificar el acuerdo de Austria con España, por otra parte, seguía con la tradicional política austriaca de debilitar al partido francés y Ensenada y continuar la antigua alianza con Inglaterra ${ }^{8}$. Mientras tanto, el embajador de Francia, el duque de Duras, llegó a Madrid en I752. Tenía buenas prendas con Ensenada, aunque el rey desconfió de sus motivos. Duras buscaba restablecer la alianza de España con Francia, e incluso especuló sobre luchar juntos en la próxima guerra contra Gran Bretaña. Todavía en septiembre de I754, Luis XV de Francia se dirigió a Fernando y le advirtió contra Austria, que nunca había superado la pérdida del trono español a manos de los Borbones9.

Al acercarse Madrid y Viena, Carvajal también acordó con Portugal el tratado de los Límites de i750. Según el acuerdo, España cedió a Portugal las siete misiones jesuitas entre los guaraníes ubicadas en la orilla oriental del río Uruguay, mientras que España ganó la importante ciudad comercial Colonia de Sacramento (actual Uruguay) para ejercer un mayor control del Río de la Plata. Sin embargo, los guaraníes y los jesuitas se resistieron a la expulsión de sus ricas tierras. Madrid y Lisboa utilizaron fuerza militar contra ambos ${ }^{\mathrm{I}}$. Al respecto, según Migazzi, Carvajal se dio cuenta que Ensenada y su aliado Francisco Rávago Noriega, el confesor real jesuita, clandestinamente minaron el tratado sin consentimiento real. El abate Facundo Mogrovejo, cliente cercano de Ensenada, transmitió cartas a los jesuitas para que se opusieran a los comisarios españoles y portugueses que establecieron los cambios de la frontera. Carvajal hizo llegar esa información a la reina Bárbara de Braganza (regía I746-I758) y al rey, quien estaba dispuesto a expulsar tanto a Ensenada como al confesor en este momento ${ }^{\text {II }}$.

La balanza en la corte se estaba decantando en contra de Ensenada. En estas circunstancias, Ensenada no intentó instalar una persona de confianza en el

7. Wolfsgruber, 1890: 51-53. Arneth, 1870: 336-341. Stollberg-Rilinger, 2017: 391, 396, 399. Whaley, 2011: 359-362, 387-388. Keene a Newcastle, Madrid, 9 de abril de 1752, en LODGE, 1933: 316, menciona la presencia de Migazzi en Madrid.

8. WOLFSGRUBER, 1890: 51-53.

9. Gómez URDÁÑEZ, 2001: 87, 90, 98-99, 109-111.

10. GómeZ URDÁÑEZ, 2001: 91-94.

11. Migazzi a María Teresa, Madrid, 19 de agosto de 1754, ff. 30-31. 
ministerio del Estado cuando Carvajal murió el 8 de abril de I754. A la vez, el rey nombró interino al duque de Huéscar, amigo del fallecido y líder de la oposición de la alta aristocracia contra Ensenada. Poco después el rey nombró titular de este cargo a Ricardo Wall, un vástago de inmigrantes irlandeses, que había sido embajador de España en Londres ${ }^{12}$. Según Migazzi, los reyes querrían mantener el equilibrio entre Ensenada en un lado y Wall y Huéscar al otro ${ }^{\mathrm{I3}}$.

Un tema discutido por la historiografía es la actuación del embajador británico, Benjamin Keene que llegó a la corte de Madrid en febrero de i749 y falleció en I757. Colaboró con Carvajal para concluir el tratado comercial de I750 entre Gran Bretaña y España, lo cual disminuyó las tensiones entre las potencias y alivió la situación de los comerciantes británicos en la península. Sin embargo, no resolvió los conflictos en América, donde madereros británicos se asentaron en la Laguna de Términos de Campeche (México), en Belice, y la Mosquitía (costa de Mosquitos, actual costa caribeña de Nicaragua y Honduras) para cortar palo de tinte. Gran Bretaña insistió en sus antiguos derechos de ocupar esas zonas, mientras Madrid los acusó de piratería. Una junta de I75I en Madrid recomendó el envío de buques de guerra, expulsar a los cortadores y vigilar la zona. Gran Bretaña destinó refuerzos, mientras que Ensenada respondió. A pesar de ello, Gran Bretaña todavía trató de salvar la paz con España ${ }^{14}$. Según Migazzi, Londres sugirió en I752 que se estableciera una empresa conjunta que talara y compartiera el beneficio hasta que se resolviera formalmente el asunto. No obstante, cuando Duras llegó a Madrid y ofreció apoyo francés, Ensenada endureció su postura y ordenó que barcos salieran furtivamente de varios puertos españoles de América a atacar a los británicos en Campeche y la Mosquitía. Keene se dio cuenta de los planes y los reportó a Londres, donde el primer ministro, el duque de Newcastle, enfrentó al embajador español Félix José Abreu y Bertodano. El embajador mandó un informe sobre las hostilidades que llegó a Madrid y perturbó gravemente a los reyes ${ }^{15}$. Este relato de Migazzi es notable ya que contradice la clásica historiografía anglosajona, según la cual Keene presentó a los reyes una copia de la orden de Ensenada interceptada por la Navy. José Luis Gómez Urdáñez desmintió esta versión de Keene a partir de las fuentes que entonces estaban disponibles, pero Diego Téllez Alarcía recientemente ha podido demostrar que Keene si contaba con una copia de la orden a dos buques de guerra estacionados en Cuba para atacar a los cortadores e incluso existían varias órdenes giradas a autoridades americanas ${ }^{16}$.

Ensenada ya perdió soporte, y Migazzi reclamó un rol importante en su hundimiento. La reina Bárbara amplió sus sospechas cuando Huéscar y Wall le dieron

12. BAUdot, 2013: 412. Gómez URdÁÑEZ, 2001: 105-107.

13. Migazzi a María Teresa, Madrid, 19 de agosto de 1754, f. 31V.

14. BAUDOT, 2013: 404-410, 414-416. Véase también GómEZ URDÁÑEZ, 2001: 95-98, 110-111.

15. Migazzi a María Teresa, Madrid, 19 de agosto de 1754, ff. 37V-38v.

16. La versión clásica se encuentra en LYNCH, 1989: 183. Véase también GómEZ URDÁÑEZ, 2001: $113,118$. BAudot, 2013: 414-416. Según TÉllez Alarcía, 2008: 180-190, Keene consiguió de espías una orden a una fragata y un jabeque en la Habana para juntarse con fuerzas de Yucatán y atacar a los británicos. La otra orden vino de una autoridad cubana desconocida. Según fuentes en el Archivo General de Indias, Ensenada también ordenó al virrey de la Nueva España, ejecutar esa empresa. 
cuenta de la secreta correspondencia de Ensenada con Paris, Lisboa, Nápoles y la que provenía de La Granja de San Ildefonso en las inmediaciones de Segovia, cuya remitente era la reina viuda Isabel Farnesio (madre del futuro Carlos III de España). Al mismo tiempo Bárbara temía que Huéscar controlara demasiado al rey y pidió su opinión a Migazzi sobre si Wall sólo pudiera contener a Ensenada si Huéscar saliera del gobierno para que ella pudiera formar el equilibrio entre las partes. Sin embargo, Migazzi aconsejó que mantener a Ensenada en el cargo significaría que Wall y Huéscar acabarían retirándose del servicio. Su astuto parecer influyó a la reina de manera significativa, según Migazzi, quien al mismo tiempo esperaba las consecuencias por su franca intervención, llegó a plantear que, de todos modos, cualquier daño que pudiera causar recaería sobre él y no en María Teresa. Además, Migazzi añadió que Sebastião José de Carvalho e Melo, primer ministro de Portugal (I750-I777) y futuro marqués de Pombal, sedujo a la reina de Portugal, María Ana de Austria (I683-I754), a reprochar a su hija Bárbara por exaltar demasiado a Huéscar y dejar caer a Ensenada.

Según Migazzi, Wall y Huéscar compusieron un memorándum para el rey que incluyó los otros tejemanejes de Ensenada. Los reyes ya tenían graves dudas sobre su ministro y cuando Wall y Huéscar presentaron sus alegaciones, se convencieron de cesar a Ensenada ${ }^{17}$. Conforme a la historiografía, en la noche del sábado el 20 de julio de I754, el rey regresó de la cacería, y Huéscar y Wall le leyeron el informe del embajador en Londres. A medianoche Wall firmó una orden real para detener a Ensenada y en las horas tempranas del día siguiente, Ensenada ya se encontraba en camino hacia Granada. Los reyes nombraron a Wall como primer ministro del gobierno quien ejerció su cargo hasta I763. Al abate Facundo, estrecho colaborador de Ensenada, también fue relevado de sus funciones y se le mandó al exilio en Burgos. Mientras tanto, Farinelli, célebre cantor castrato, amigo de Ensenada y confidente de la reina, se mantuvo hasta el fallecimiento del rey en $\mathrm{I} 759^{\mathrm{I} 8}$.

En las palabras de Migazzi, salieron a la luz más planes Ensenadistas después de su caída. Fernando estaba muy indignado al escuchar que Ensenada había encargado a mercaderes de Silesia (Prusia / antes Austria) la instalación de una fábrica de telas de lino, aparentemente para dañar la fábrica de lino que Carvajal y Lancaster había puesto en León. De igual forma el rey tuvo conocimiento que Ensenada prestó dos millones de pesos a Isabel Farnesio, que conspiró a favor de sus hijos ${ }^{19}$.

Tal parece que la conducta de Ensenada no era inusual para la época. El Staatskanzler Kaunitz de María Teresa también manejó el ministerio de Estado eficazmente. Muchos lo vieron como despotismo insidioso, y la reina con el tiempo lo consideró opresivo e incontrolable. Otro ministro, por ejemplo, criticó en 1757 «que muchas cosas suceden y son decretadas sin el conocimiento y mucho menos la aprobación de Vuestra Majestad,» y la reina respondió que es «demasiado cierto y ya no puedo evitarlo.» Adicionalmente, el padre de María Teresa, el emperador

17. Migazzi a María Teresa, Madrid, 19 de agosto de 1754, ff. 32-32v, 34, 35V, 37v-38v.

18. Gómez URdáñez, 2001: 110-113. Téllez Alarcía, 2008: 191-192.

19. Migazzi a María Teresa, Madrid, 19 de agosto de 1754, f. 40-40v. 
Carlos Vl, tenía un ministro clave que era tan experimentado como codicioso y desleal. Actuaba con opacidad deliberada y se decía que estaba a sueldo de reinos extranjeros. Sin embargo, el ministro gozaba de la ciega confianza del emperador ${ }^{20}$. Mientras tanto Ferdinand y Bárbara, a menudo tachados de débiles, consideraron que las cabriolas de su primer ministro superaron lo aceptable y lo destituyeron.

Migazzi se quedó en Madrid hasta I756, y al regresar a la corte de Viena ascendió aún más en la jerarquía eclesiástica, a pesar de las críticas que recibió por su labor diplomática. El siguiente año, su sucesor en Madrid destacó la inapropiada injerencia y equivocado partidismo de Migazzi por Gran Bretaña, pero hay que tomar en cuenta que escribió su relación con posterioridad a la reversión de las alianzas, cuando Austria había forjado la alianza con Francia ${ }^{21}$. Sin embargo, María Teresa aparentemente apreció los esfuerzos de Migazzi, quien además se presentó como partidario de una reforma de la Iglesia católica. Migazzi fue nombrado obispo de Vác / Waitzen (Hungría) en 1756 y arzobispo de Viena al año siguiente. Con el tiempo su conducta cambió y para mediados de la década de i760 sus posturas eran más conservadoras, convirtiéndose en un acérrimo opositor a las posteriores reformas eclesiásticas del emperador José Il, hijo de María Teresa. Provocó irritaciones en la corte y se le apartó de la política en su mayor parte. Migazzi falleció en I8oz y fue enterrado en la catedral de San Esteban de Viena ${ }^{22}$.

Su biógrafo del siglo XIX, Cölestin Wolfsgruber, consultó la correspondencia de Migazzi incluso la que está cifrada. El historiador cita algo menos de media página de la relación del i9 de agosto de I754 en su libro, pero el restante de las once fojas de la relación no ha sido publicado, ni estudiado a profundidad. Aparte de este, historiadores de Austria y España publican y analizan la correspondencia entre Viena y Madrid hasta el fin de la Casa de Habsburgo en España y la Guerra de Sucesión española (I7OI-I4) y para el periodo posterior a I759, pero hasta ahora no han publicado la correspondencia de Migazzi en Madrid²3.

\section{CRITERIOS DE LA EDICIÓN}

Migazzi escribió varias cartas justo después de la caída de Ensenada y la más extensa es la relación del i9 de agosto de i754. Migazzi usó la caligrafía alemana cursiva Kurrent, que se distingue de la mano latina, en la cual Migazzi sólo anotó palabras de origen extranjero, como para los casos de nombres de ciudades, pueblos y personas. En la presente reproducción no se distinguen las dos. Se hizo una paleografía fiel del manuscrito en alemán y se le convirtió a la letra mecanografiada sin alterar la ortografía. Además, hay que recordar que no existía un estándar universal ortográfico del alemán en aquel entonces.

20. Stollberg-Rilinger, 2017: 86, cita en p. 242.

21. TÉllez AlarCia, 2008: 155. Hay que añadir que este autor cita al embajador francés parafraseando a Migazzi.

22. Hersche, 1994: 486-487. 1970.

23. Wollfsbruger, 1890: 52. Edelmayer, León Sanz \& Ruiz Rodríguez, 2008. Véase también JuretschKe, 
Se desataron las abreviaturas, indicando el texto añadido en itálicas, como, por ejemplo, en el caso de Kaÿserl. Maÿtt = Kaÿserliche Maÿestät (Majestad Imperial). La duplicación de una consonante indicada mediante una sobrelínea como la «m̄ en, por ejemplo, «vorzim̄er / Vorzimmer», y la ligadura en la palabra «Europae» se resolvieron de esta manera. Además, las letras «ì $\mathrm{y}$ «j» $\mathrm{y}$ «ÿ» $\mathrm{o}$ «u», «ü» $\mathrm{y}$ «v» se representan fielmente, como, por ejemplo, «ieden» (cualquier). La «s» escrita de forma elongada en el original se representa como la «s» estándar, y consonantes dobles «ff», «sß» $\mathrm{y}$ «tt» también corresponden al original. Las mayores dificultades fueron las mayúsculas, que se distinguen del uso moderno. Hemos intentado ceñirnos lo más posible al original, con algunas excepciones: Las palabras al principio de las frases se escriben en mayúsculas según el uso actual, a veces incluso diferenciándose del original. Para la mayoría de las letras al principio de las palabras («a», «e», «g», «i», «l», «m», etc.) en lo general se puede distinguir fácilmente entre mayúsculas y minúsculas, y en casos de duda hemos anotado las minúsculas. De las letras «b», «h», «t» $\mathrm{y}$ «v», sólo se utilizó una forma de letra, por lo que se presentan en minúsculas, incluso las que aparecían al principio de las palabras.

Errores en el manuscrito original se explican con una nota a pie de página. En algunos casos, la ortografía no sólo refleja el estilo personal de escribir, sino que parece también corresponder con la pronunciación de la zona de habla alemana del sur. El autor indica la elongación y el redondeo / desredondeo de algunas vocales, por ejemplo, Migazzi anota «solte» que indica una «o» larga en vez de la vocal corta del estándar de hoy «sollte» y «gienge» en vez de «ginge». De modo similar, Migazzi escogió «ihme», «Entschlüßung», «Eüer», y «kunnte». Además, dado que muy probablemente no se trata de un borrador sino de la carta misma, sólo una vez se corrigió una palabra: Migazzi quitó el prefijo y sufijo de «vnterredungen (conversaciones)» y corrigió el restante para que saliera «reden (discurso o habla)».

He intentado una traducción fiel que refleje el estilo del siglo XVIII hasta cierto punto, aunque se realizaron algunos ajustes para entender mejor el texto. Por ejemplo, Migazzi usa frecuentemente la palabra «höchst Selbe» o «Allerhöchst dero» que significa «ella altísima misma» cuando refiere a María Teresa u otras realezas. En vez de esto, en documentos españoles de la época se solía usar formas como «Su Alteza» o «Su Majestad», pero repetirlas varias veces en vez de usar el pronombre personal «ella», especialmente cuando una frase ya empezó con «Vuestra Majestad», haría que la lectura sea más pesada. Por lo cual, «Allein alß beÿde Maÿestäten ihm den nemmlichen tag Gnädigst zu erkennen gaben, daß höchst deroselben ... nicht gleichgültig gewesen seÿn», se traduce como «cuando ambas Majestades le revelaron clementísimamente el mismo día que ellas ... no eran indiferente». Además, la «allerdurchlauchtigstes Ertz-Hauß» se reproduce como la «Augustísima Casa», tal como era costumbre. ${ }^{24}$

Asímismo, Migazzi tradujo los títulos españoles a veces al estilo francés e italiano. Muchos en la corte de Viena manejaron tanto el francés como el italiano y tenían amplio contacto con ambas culturas. La propia María Teresa usó el dialecto de

24. Migazzi a María Teresa, Madrid, 19 de agosto de 1754, f. 39v. 
Viena que le había enseñado su nodriza, y hablaba y escribía con su familia y otros aristócratas tanto en esa lengua como en francés y a veces en italiano. Además, la reina había aprendido español y latín ${ }^{25}$. Probablemente, Migazzi era un hablante nativo bilingüe de italiano y alemán, y servía tanto en Roma como en Viena. Seguramente, Migazzi también manejaba bien el francés, español y latín. Esto explica por qué Ensenada se escribe en la relación como «Marquis d'Enzenada», el duque de Huéscar como «Duc d'Huescar» o simplemente «Duc», mientras su sucesor era «du Wall» en un caso. El embajador británico se apuntó como Kéene. ${ }^{26}$ En otras cartas de Migazzi incluso aparece la Puerta de Antocha como «Antoggia», el marqués de la Ensenada como «Marchese», y su asistente como «Ordegnana», en lugar de «Ordeñana». ${ }^{27}$

Por último, Migazzi en varios casos convirtió la terminación del apellido italiano Farinelli en una «o» parecido al latín, al estar su nombre en el caso dativo, es decir, el objeto indirecto, de la frase en alemán. En una ocasión, declinó su apellido como «Farinellj», al estar en el genitivo. Sin embargo, las reglas eran probablemente aún menos fijas y Migazzi no era siempre consistente. Por ejemplo, la preposición «gegen (frente a)» exige el acusativo, pero Migazzi probablemente pensó más en «gegenüber (frente a)» con el dativo al escribir «von ihrer verschwiegenheit gegen Farinello». El caso de «Er Farinello wurde selbst der erste gewesen seÿn / Farinelli el mismo habría sido el primero», es en el nominativo. Esas sutilezas aparecen en la transcripción, pero en la traducción modernicé los nombres propios.

\section{DIE RELATION DES GRAFEN CHRISTOPH MIGAZZI AN MARIA THERESIA, MADRID, 19 AUGUST 1754}

[fol. 29r] Allerdurchläuchtigste Großmächtigste Römische Kaÿserin, auch zu hungarn, und böheimb Regierende Königin,

Allergnädigste Kaÿserin, Königin, und Frau Frau!

Wann der ausschlag deren Sachen zur rechtferttigung des in denenselben gehabten antheils zureichend wäre, so dörffte mir nicht vergebens schmeichlen, das der vmsturtz des Marquis d'Enzenada meinen diesfallß gemachten schritten das worth sprechen wurde; allein gleichwie Eüer Kaÿserlichen Maÿestät nicht, nach den schier allgemeinen vorurtheil ${ }^{28}$ deren meisten menschen, von dem glücklich= oder wiedrigen erfolg einer vnternehmung, sondern vielmehr von der art, wie Solche betrieben worden, Weislichst

25. Stollberg-RILINGer, 2017: 54

26. Migazzi a María Teresa, Madrid, 19 de agosto de 1754, ff. 29-32.

27. Migazzi a Kaunitz, Madrid, 22 de julio de 1754, ÖStA, HHStA, StA, DK, caja 85, expediente 3, no. 16, sin foliación.

28. Heute wohl «Urteil» (juicio). 
[fol. 29v] zu urtheilen pflegen, also werden Allerhöchst Selbe zu erlauben geruhen, das mich vor diesmahl von dem in betreff meiner Selbst mir gemachten vorsatz, alß da ist, entweder gar nichts, oder so kurtz und beschränckt alß möglich, von mir selbst zu sprechen, in etwas entferne, und die Sach von ihrem vrsprung herhole, um nachmalß auf jenes zuverfallen, was mich zu überreichung des bekannten blatts bewogen, und vermöget hat.

Schon zur zeit des Seeligen Carvajals ware mir zuverläßlich bekannt, das die Regierende Königin Jhr großes einmahl in Enzenada gesetztes vertrauen geminderet, ob deßen betrag verdacht geschöpfet, und sich auf des Carvajals seiten gewendet habe. Gleichwie aber dieser Ministre theils auß verachtung gegen Enzenada, theils auß seiner ihme anklebenden kleinmüthigkeit sich niemals mit ernst, und standhafftigkeit wieder Solchen an Laden hat legen wollen, so verblieben die Sachen zwischen beÿden also abgewogen, das Einer über den anderen nicht wohl die oberhand gewinnen kunnte. Weiters bekame ich sichere außkunfften, das die Königin mehr erwehnten Carvajal zum öffteren ermahnet hatte, dahin beflißen zu seÿn, das Er einige standhaffte proben deren dem Enzenada angeworffenen beschuldigungen aufbringe, um sodann mit rechtem Grund wieder Solchen verfahren zu können. Allein Carvajal zu gleicher

[fol. 3or] zeit, alß er unabläßlich den üblen stand deren Sachen beklagte, machte er sich eine gewisßens= und wieder seine geburth lauffende Sache darauß, entweder einen dritten, und sonderbar von des Enzenada vntergebenen zur sprach zu bringen, oder aber die häuffige an Enzenada gekommene brieffe zu öffnen. Wenig zeit vor seinem todt befreÿete Er sich von dieser in seiner stelle allzuweit getriebenen gewisßens-ängstigkeit, und fiele es ihm nicht schwer, viele, und wichtige wieder Enzenada redende vrkunden zu handen zu bekommen; durch einen vnverhofften zufall wurde Er auch in stand gesetzet, sich solcher briefschafften zu bemeisteren, welche klar an tag legten, das der beichtvatter an der, wieder die Spanisch= und Portugesische zu festsetzung derer Gräntzen abgeschickten Ingenieurs, von denen Indianern bezeigten wiederspenstigkeit einen nicht geringen antheil hatte, indeme Er beichtvatter die beÿ solchen völckeren sich aufhaltende Missionarios aufmunterte, beÿder Cronen befehlen keine folg zu leisten, wie dann auch in der thatt gedachte Indianer die Spanisch= vnd Portugesische Commissarios abgetrieben, und freÿ erkläret hatten, daß sie niemand anderen, alß denen Patribus Societatis Jesu den gehorsam schuldig wären. Ein Neven des Don Facondo ließe sich zum vnterhandler, und übertrager solcher briefschafften gebrauchen,

[fol. 30v] und Enzenada ware in dieser gantzen vnordnung mit dem beichtvatter einverstanden. Da nun Carvajal von seiner schlaff-sucht erwachet ist, und die schönste zubereittungen machte, um Erstlich die Königin, und nachmals mit höchst Jhro einwilligung den König von so gefährlich= und häßlichen räncken zuverständigen, überfiele ihn der vnvermuthete todtesschlaff, welcher seine augen, und mund auf beständig verschlosßen hat: Doch redeten seine hinterlaßene Schrifften, in welchen von ihme alles genau aufgezeichnet, und dem König darüber seine meinung deütlich ist eröffnet worden. Gleichwie desßen vnpäßligkeit sich gleich 
beÿ ihrem anfang sehr gefährlich gezeiget, und Jhn auch in dem kurtzen bezirk dreÿer tägen von dieser Welt entrisßen hat, so wurden in des Enzenada hauß sehr viele heimliche zusammenkunfften gehalten, und in solchen der schluß genommen, das Er Enzenada zwar still, und ruhig sich halten, von seinen anhängeren hingegen all=mögliches gethan werden solte, um die zur erledigung eilende stelle ihme zu verschaffen. Duras ware von allem verständiget, und vnterließe Er auch seines orths nichts, was den gefaßten vorschlag beförderen kunnte. Ich hingegen hatte das glück gehabt, ein anständiges Mittel zufinden, durch welches die Regierende Königin geziemend ersuchen ließe, beÿ einer so wichtig= alß hacklichen ${ }^{29}$ Gelegenheit Eüer Kaÿserlichen Maÿestät sich zu erinneren: und in der thatt wurde ich Sonntag

[fol. 3Ir] abends in dem vorzimmer des sterbenden Carvajals in höchst Jhro nahmen versicheret, das niemand, der Eüer Kaÿserlichen Maÿestät verdächtig seÿn kunnte, zur verwaltung deren außländischen geschäfften gelangen würde. Waß sich diesfalls weiters zugetragen, werden Eüer Kaÿserliche Maÿestät auß meinen dem Courier Prennschitz mitgegebenen allerunterthänigsten berichten zu entnehmen geruhet haben. Enzenada, Duras, und ihre anhängern wurden zwar von dem Jnterino des Duc d'Huescar sehr niedergeschlagen; sie erholten sich aber in balde, und verdoppleten ihre bemüheungen ${ }^{30}$, um gemeldten Duc von denen geschäfften auf allezeit zu entfernen. Was vor schädliche vorurtheil man wieder Solchen der Königin beÿzubringen, wie der beichtvatter diesfallß die nemliche absichten des Enzenada zubetreiben, und des Königs gewisßenszärtligkeit sich zu nutzen zu machen gesuchet habe, ist Eüer Kaÿserlichen Maÿestät ebenfalls bekannt.

Wann es dazumahl nach den ersten trieb, und eÿffer des Catholischen Königs gegangen wäre, so wurde sowohl Enzenada, alß der beichtvatter ihre hoffnung auf einmahl abgeschnitten, und beÿde sich ausßer ihren stellen gesehen haben. Sehr Leicht wurde es dazumahl dem König gefallen seÿn, eine dergleichen entschlüsßung zu nehmen, weilen Jhme eines theilß die herrschende Art des beichtvatters, und daß andurch aufgedrungene joch schwer, und Empfindlich, Anderen theils aber des Enzenada, deme Seine Maÿestät ohnehin nie

[fol.3IV] gewogen waren, betrag, und verwaltung höchst Jhro verdächtig zuwerden anfinge. Jn Solcher deren Sachen verfasßung wurde des Walls benennung allbereit ruckbar $^{3 \mathrm{I}}$, und nahmen dahero offtgedachter Enzenada, und beichtvatter samt der gantzen frantzösischen partheÿ davon anlaß, beÿ beÿden Maÿestäten sich wieder Huescar auf das emsigste zubestreben. Bë̈ dem König ware kein mittel zureichend, um Seiner Maÿestät gegen Huescar tragende zärtligkeit zu erkalten: Die Königin ware zwar auch nicht zubewegen, Jhr voriges vertrauen, und Gnad dem Enzenada zuruckzustellen, doch wurden höchst Selbe in einige verlegenheit mit deme gesetzet, das man Jhr vorstellig machte, wie Huescar nicht Lang um den König seÿn wurde,

29. Heute wohl «heikel» (delicado).

30. Bemühungen.

31. Ruchbar. 
ohne die Oberhand über alle zugewinnen; da einmahl das gegengewicht verlohren wäre, dörfften Seine Maÿestät daß erste opfer seines vnmäßigen hochmuths werden: Hingegen wurde Wall, auch ohne des Huescar beÿwürkung, vermögend genug seÿn, den Enzenada in gehörigen schrancken zuhalten, und müste Er Wall zu gleicher zeit Jhro Maÿestät der Königin dienst immerdar zugethan bleiben, weilen er sich ohne dero schutz in die länge nicht aufrecht erhalten wurde: worauß dann die weitere folge flüsßete, das beÿ einer so zertheilten, und mit gleichen kräfften gegen einander streittende macht, Jhro Maÿestät die Königin die waage immerdar nebst der Freÿheit in händen behielten, solche nach eigenen wohlgefallen, und willkur zu Lencken.

[fol.32r] Huescar im wiederspiel hatte den festen vorsatz gemacht, entweder vom hoff sich zu entfernen, oder den Enzenada gestürtzet zu sehen: Es ware auch diese entschlüßung um so Leichter von ihm zu nehmen, alß Er auf des Walls Freündschafft einen sicheren staatt machen kunte. Farinelli seines orths, lage gleichfalls der Königin zu gunsten des Enzenada beständig in denen ohren, und ware mir zuverläßlich bewust, das eben diese Seine vorgemeltem Ministre hegende blinde Freündschafft die eigentliche vrsach gewesen seÿe, wegen welcher Seine Maÿestäten Selbst auß allem dem, was nach des Caravajals todt vorgefallen ist, ihme Farinello ein geheimnus gemachet haben. Diese nun auß so verwickelten vmständen in der Königin gemüth erregte vnruhe, und zweiffelhafftigkeit bewogn höchst Selbe, mich befragen zu lasßen, was mir von des du Wall außwahl eigentlich schiene? Die Frage ware nicht trucken, sonderen nach denen erst berührten vmständen eingerichtet, und nach maas derenselben wurde meine meinung abgeforderet: Ob nemmlich Wall ohne den Duc d'Huescar stärcke genug haben wurde, dem gleich einem stromme alles um sich reisßendem Enzenada einhalt zu thun? Ich glaubte dahero meiner pflicht kein genügen geleistet

[fol. 32v] zu haben, wann ich beÿ einer so wichtig= und von dem Wohl des Allerhöchsten diensts entscheidenden gelegenheit nicht klar, und deütlich gewesen wäre: Es stunde mir auch, wenigstens so weit die menschliche behutsam= und vorsichtigkeit reichen kann, nicht das geringste zu befahren. ${ }^{32}$ Von der Königin ehrlich= und edlen gemüth, von ihrer verschwiegenheit gegen Farinello, und allschon beÿ denen Letzteren zeiten des Caravajals geschöpften, nach deßen todt aber mercklich vermehrten argwohn wieder Enzenada kunnte ich mich vollkommen überzeiget halten, und ware es nicht das Erstemahl, das höchst selbe, in Jhren eigenen vorfallenheiten, meine geringe meinung anbegehren zu Lasßen, mir die allerhöchste Gnad erwiesen haben: Welches ich aber beÿ mir selbst verschlosßen zu halten der Ehrligkeit, dem gewisßen, und Eüer Kaÿserlicher Maÿestät dienst gemäß zu seÿn erachtet habe. Jn deme bestehet nun, Allergnädigste Frau! deren Sachen wahrer hergang: Allein geruhen Eüer Kaÿserliche Maÿestät allermildeß, dero Lebhaffteste einbildungs-krafft von der erst berührten zusammenfügung so merkwürdiger vmständen auch nur auf einen augenblick abzuführen, und Lediglich Allerhöchst

32. «Befahren» im Sinne von «befürchten» oder «sorgen» (temer). 
dero erleichtesten ${ }^{33}$ Einsicht vorzustellen, daß die zweÿ wiedrign partheÿen so Lebhafft gegen einander strietten, das ohnmöglich mehr in die Länge

[fol. 33r] das gleichgewicht zwischen Jhnen bestehen, sondern nothwendig eine auß beÿden den meister spielen müste. Eine gienge der anderen, also zu reden, auf das Leben Loß, doch mit dem vnterschid, daß Enzenada sich begnüget hätte, durch heimliche kunst-griffe, und räncke sich zu erhalten, den Huescar andurch abzumatten, und endlichen zu jener entschlüßung zu vermögen, welche der Duc in der thatt genommen hatte, beÿ wiedrigen außschlag deren Sachen den hoff zuverlaßen. Wall wurde nachmalß sich in der nothwendigkeit gefunden haben, entweder vor Enzenada zu biegen, oder, was wahrscheinlicher gewesen wäre, seinem Gönner, und Freünd dem Huescar nachzufolgen; da einmahl die gutspanisch gesinnte zerstreüet, und die Frantzösische Partheÿ die gantze Macht, und gewalt an sich gezogen hätte, so veroffenbaren sich von Selbst iedermänniglich die höchst-schädliche folgen, welche der allgemeinen Ruhe Europae, und dem so eng damit verknüpften wohlseÿn Eüer Kaÿserlichen Maÿestät geschäfften, zum grösten nachtheil Spaniens selbsten, zugeflosßen wären. Die Sachen Ließen kein mittel zu. Enzenada kunte nicht neben Huescar und seinem Anhang, und Huescar wolte nicht neben Enzenada bestehen: welches so viel sagen will, daß der von denen grösten dingen entscheidende

[fol. 33v] Augenblick angekommen ware, entweder spanien unter dem Frantzösischen Joch wiederum versencket, oder in Jhrer Würde, und Freÿheit erhoben zu sehen. Es ware nicht darum zu thun, ob das Kriegs= und See=weeßen, die schätze Indiens, und Spaniens in Enzenada, oder eines dritten händen verblieben: solches wäre mir in so weit gleichgültig gewesen; sondern die Sachen kamen darauf an, daß dieses zu dem Ruhestand Europae so viel beÿtragendes König Reich die augenscheinliche gefahr lieffe, ein sicherer werkzeüg deren so gemeinschädlichen Absichten des Frantzösischen hoffs zu werden.

Jn einer so gefährlichen Crisi, wann ich auch die vorgehende von mir angezeigte versicherungen ob der geheimhaltung meiner schritten nicht gehabt hätte, so wurde doch dem ewigen vorwurff meines Gewisßens mich außgesetzet haben, fallß jener Mittlen mich nicht gebrauchet hätte, welche die Göttliche vorsichtigkeit zur ablehnung eines so vngeheüren vngewitters mir nicht vmsonst an handen geben zu wollen geschienen hat. Die gleichgültigkeit zwischen beÿden partheÿen wurde vor Eüer Kaÿserlicher Maÿestät dienst den Enzenada gewieslich nicht gewunnen, den Huescar, und Wall hingegen wurde ich andurch gantz sicher verlohren haben; vnd wurde sodann die große Lieb, und aufrichtigste Freündschafft der

[fol. 34r] Regierenden Königin vor Eüer Kaÿserliche Maÿestät nicht zulänglich gewesen seÿn, die dermahlige gute einverständnuß beÿder allerhöchsten höffen zu erhalten, fallß Ensenada das feld behaubtet hätte. Allein erlauben Eüer Kä̈serliche Maÿestät, auch den schlimmsten fall zusetzen, das nemmlichen Enzenada würklich

33. Erleuchtesten. 
über die gutgesinnte die oberhand gewunnen hätte: So wurde alsdann, meinen geringen ermessen nach, eine solche vnternehmung von mir gewaget worden seÿn; wovon der nutzen auf Eüer Kaÿserlichen Maÿestät, der schaden hingegen Lediglich auf mich allein fallen kunnte. Jch wurde der erste gewesen seÿn, welcher mich beÿ allerhöchst deroselben angeklagt, und zugleich erkläret haben wurde, das, nachdem das wiedrige verhängnuß spaniens solches Königreich in die hände seiner grösten Feinden geliefferet hätte, dem dienst Eüer Kaÿserlichen Maÿestät mein fernerer aufenthalt allhier ohnmöglich mehr ersprießlich seÿn kunnte, indeme von denen jenigen, so das Ruder führeten, noch vertrauen, noch gewogenheit anzuhoffen hätte. Eüer Kaÿserliche Maÿestät wurden durch meine abruffung klar an tag gelegt haben, daß allerhöchst dieselbe meinen betrag mißbilligen, und wurde andurch die gantze schuld bloß mir allein von iedermänniglich zugemuthet worden seÿn.

[fol.34v] Eüer Kaÿserliche Maÿestät werden sich allermildest zuruck zu erinneren geruhen, daß, da beÿ meiner zuruckkunfft von Rom, mir von Einigen in Wienn zuverstehen gegeben worden, das die allergnädigst mir zugedachte Coadjuterie von Mechlen dem allerhöchsten dienst in Niederlanden einige nachtheil verursachen dörffte, ich solche zu Eüer Kaÿserlichen Maÿestät füßen alsogleich abzulegen mich vrbiettig erkäret habe. Wann nun eine ewige versorgung, in betrachtung Eüer Kaÿserlichen Maÿestät dienst mir gleichgültig geworden ist, hätte ich wohl nachmalß ein bedencken tragen sollen, mich der gefahr außzusetzen, eine zwar sehr glantzende, und meine fähigkeit weit übersteigende, doch aber anbeÿ nur zeitliche bedienung zu verliehren, um einen schritt zu wagen, deßen glücklicher erfolg die sachen ungemein verbesßeren, der wiedrige aber nichts verschlimmeren kunnte? Übergehe viele andere vmstände, welche zwar beträchtlich, doch der sache, wovon die frage ißt, nicht weesentlich seÿnd: vnd bleibet mir dahero nichts übrig, alß nach einen so offenhertzig=, und aufrichtigsten bekanntnuß, Eüer Kaÿserlichen Maÿestät erleichtesten beurtheilung meinen hierunter gehaltenen betrag allerunterthänigst zu vnterwerffen.

[fol. 35r] Eüer Kaÿserliche Maÿestät geruhen nun weiters allergnädigst genehm zu halten, das ich die wahre vrsachen, welche deß Enzenada vmsturtz beförderet, und die geheime vmstände, welche solchen entweder vorgetretten, oder begleitet haben, allhier allervnterthänigst anführe. Wall hatte beÿ der rucksendung des an Jhn nacher Londen abgeferttigten Couriers einige wenige höffligkeits=zeilen an Enzenada erlasßen, zugleich aber dem Duc d'Huescar deütlich, und weitläuffig zuerkennen gegeben, das falls seine abruffung von Londen die staatts-Secretairie zum gegenstand haben solte, er solche anzunehmen nicht gesinnet wäre, und sein haubt-anstand seÿe des Enzenada gewalt. Alß der König von Huescar sowohl des Walls brieffe an Enzenada, alß auch die abneigung vor die ihm gewiedmete stelle vernahme, befahlen Seine Maÿestät das schreiben zuverbrennen, und, das zweÿte belangend, trugen höchst Selbe dem Duc d'Huescar weitershin auf, einen Courier an die Gräntzen spaniens dem Wall in geheim entgegen zuschicken, damit Er den tag seiner eintreffung nacher Alcala benachrichten, und alldort von ihme Huescar vorläuffig besuchet, und vor seinem eintritt in Aranjuez von des Königs eigenlichen 
[fol.35v] Willens-Meinung vnterrichtet werden könnte. Wall faßte beÿ der ersten vnterredung mit Huescar alsogleich den schluß, neben Enzenada nicht dienen zu wollen: und Huescar erneüerte seinen alten vorsatz, beÿde in der absicht, Spanien von einem so verderblichen Mann zu befreÿen, und ihr andurch den so sehr verfünsterten Glantz, und das vorige ansehen wiederum zuruck zustellen. Von dem augenblick waren sie bedacht, solcher proben sich zuversicheren, durch welche die Königin von des Enzenada geheimen brieff-wechsel mit Franckreich, Portugal, Neapl, und St. Ildefonso unwiedersprechlich überführet wurde. Gleichwie das Maaß dieses Mannes erfüllet ware, so Ließe Er sich durch eine allzugroße sicherheit einschläfferen, und gabe andurch anlaß, das seine, und seiner anhängeren brieffe in die hände dieser zweÿen aufgeweckten, wackeren, und geschickten Männeren verfielen. Nachdem sich nun diese beÿde mit zulänglichen proben versehen, und außgerüstet sahen, wurde von ihnen eine schrifft verfasßet, in welcher Sie theilß des Enzenada geheimen brieff-wechsel mit gedachten außwärtigen höffen, theilß seine schädliche, und üble verwaltung in dem Jnnerlichen klar vor augen Legten. Die zu boden liegende Kriegs=Macht, die vnnutze vnternehmungen in dem See-Weesen, die

[fol. 36r] verschwendung so vieler Millionen, die Despotische herrschung in allen dingen dieses eitlen Manns, machten den gegenstand des letzteren satzes der zu überreichenden Schrifft auß. Der Königin wurde dieses blatt mitgetheilet, und nachdeme höchst Selbe einige der gedenckens-art des Königs anständige abänderungen darinnen anbefohlen hatten, gaben Sie dem Huescar, und Wall erlaubnuß, beÿ dem König den weiteren gebrauch davon zu machen. Man hatte zwar andurch vieles gewunnen; allein kame der haupt-anstand auf den beichtvatter an, weilen solcher sich gäntzlich auf des Enzenada seiten gewendet, und dem König dieses Manns treffliche eigenschafften, und vnschätzbare verdienst immerdar anrühmte. Allein da Gott sein Werck ausführen will, so giebt Er auch denen Jeningen, welche die vollzieher, und werkzeüge seinen Willens seÿn solten die anständige Mittel an handen: Der aufrührische betrag deren Indianischen lesuiten, des beichtvatters geheime einverständnus mit denenselben, und die weitere von Huescar, und Wall in dieser Sache überkommene bestättigungen gaben Jhnen zu Länglichen stoff, dem König seinen gewisßens anführer verdächtig zu machen: und gleichwie Solcher die Enzenadische partheÿ so offenbar ergriffen, und sich mit Don Facondo, und mehreren anderen

[fol. 36v] von dergleichen gesünde so eng vereiniget hatte, so wurde Er von denen nemlichen Waffen verwundet, mit welchen Er anderen einen tödtlichen stosß beÿzubringen glaubte. Es ware dahero Lediglich um die außwahl einer bequemen zeit zu thun, um den König von so wichtigen dingen zuverständigen. Jn Aranjuez waren Seine Maÿestät die letztere zeit einigen kleinen gesundheits=anstößen, und der Melancoleÿ vnterworffen, dahero die ruck-kunfft nacher Madrid abgewartet werden muste: Die Konigin versaumte indesßen keine Gelegenheit, um in dem hertzen des Königs die zärtligkeit gegen Huescar, in seinem gemüth aber die hochschätzung vor dem Wall zu unterhalten, ob des beichtvatters, und Enzenada betrag hingegen einigen argwohn hervorblicken zu lasßen. 
Enzenada, ob Er zwar nicht gäntzlich mißkennen kunnte, daß die enge vereinigung des Huescars und Wall, unter anderen auch seine verkleinerung zum gegenstand haben dörffte, auch desthalben von einigen Seiner Freünden auf guter hut zu seÿn ermahnet wurde, so bauete Er dennoch auf des beichtvatters, vnd Farinellj vermogenheit so viel, daß Er alle wiedrige bemühungen gering, und Fruchtloß schätzte. Niemahlß ließe Er sich beÿgehen, daß die Catholischen Maÿestäten zu einer beträchtlichen entschlüßung kommen wurden:

[fol. 37r] ohne das der König solche mit dem beichtvatter vorläuffig überschlagen, und die Königin dem Farinello davon sprechen solte.

$\mathrm{Vm}$ die mitte des vorigen Monaths wurde nun der angriff gewaget, und ehe alß Huescar, und Wall dem König ihr vorhaben aufzudecken anfiengen, batten sie sich von beÿden Maÿestäten daß engste, und heiligste geheimnus auß. Der König gabe ihnen das worth, mit vermelden: wie Er schon vor einiger zeit bemerket hätte, das sie Jhm etwas wichtiges vorzutragen gedencketen; Sie solten sich aber versichert halten, das Er sich nicht darüber beunruhigen, sondern Lediglich, was recht, und billig ist, thun wurde. Von dem beichtvatter machten sie dahero den anfang, und schrietten von dannen weiters zu Enzenada; die sach gienge auch so glücklich, daß in zweÿen vorstellungen, der bekannte schluß genommen wurde. Der König wolte sich auch des beichtvatters befreÿen, allein wuste man nicht auf der stelle iemand anderen vorzuschlagen, weil die jenige, in welche der König ein vertrauen hatte, zu annemnung ${ }^{34}$ dießes ambts nicht zu bewegen waren: Es ware auch dem Huescar, und Wall nicht viel mehr an dem beichtvatter gelegen, weilen, da der König einmahl ein so gegründetes mißtrauen wieder Solchen gefasßet hatte, deßen vorstellungen beÿ

[fol. 37v] Seiner Maÿestät nicht Leicht mehr einen eingang finden Wurden: vnd in der thatt, nach dem fall deß Enzenada hat sich der beichtvatter von keiner sache dem König zu reden getrauet, Seine Maÿestät aber sich gegen Jhn lediglich in der bloßen beicht beschräncket. Mit allem dem dörffte es mit dem beichtvatter in die Länge nicht halten.

Ein vnvermutheter, anbeÿ aber sehr wichtiger zufall mag wohl des Enzenada vmsturtz beförderet haben. Eüer Kaÿserlichen Maÿestät wird ohnfehlbar allergnädigst bekannt seÿn, wie unter denen zwischen spanien, und Engelland noch nicht richtig gestellten puncten das große Moß von Campeche in Jndien einer deren grösten anständen ist, indenen in diesem vnbewohnten, und sehr vngesundem strich Landes sich einige Engelländer niedergelasßen, und das alldortige zu färbung deren tücheren vngemein dienliche holtz zu fällen angefangen haben: Da hingegen Spanien dieses vnternehmen alß einen eingriff in ihrer gerechtsame ansehen will. Schon allbereit vor zweÿen Jahren wurde von seiten Engellands ein vergleichungs-Mittel im vorschlag gebracht, daß nemmlichen beÿder Cronen vnterthanen eine Compagnie auf etwelche Jahr errichten, und den gemelten holtzschlag,

34. Annehmung. 
biß zu förmlicher erörterung der Sache, gemeinschafftlich vornehmen solten. Enzenada schiene diesen vorschlag zu bequehmen, vnd versicherte den Keéne, daß man darüber zusammen kommen wurde.

[fol.38r] Allein ist die Sache von einer zeit zur anderen geflisßentlich verschoben worden, biß endlich Keéne in gewiese Wisßenschafft kame, das nach des Duras anherokunfft von dem Enzenada auf gantz andere gedancken verfallen, und ein neüer von einem dritten gemachter vorschlag gutgeheißen worden seÿe, desßen innhalt vorzüglich dahin lauthete, das die Engelländer vom gedachten Campeche, von der Küste Muschitto, und von dem fluß Tinto mit gewalt abgetrieben werden müsten. Enzenada hatte auch Würklich vor einigen Monathen, in gröster geheime, befehle ergehen Lasßen, daß einige Schiffe von vnterschiedlichen Spanischen häven, außlauffen, sich in einer gewiesen entfernung von Muschito vereinigen, und Feindseelig auf die Engelländer Loß gehen solten: Alß einmahl die Feindseeligkeiten angefangen worden, wurde Enzenada die gantze schuld auf Engelland geladen, und den Catholischen König wieder Seinen willen in die frantzösische hände geworffen haben. Duras, und desßen anhängern waren dabeÿ so unbehutsam, das sie sich vernehmen Ließen, wie der Frieden mit Engelland wenige Monath mehr dauren, und folglichen die verknüpfung zwischen Spanien, und Franckreich eben so, wie unter dem Seeligen König Philippo ${ }^{35}$, hergestellet, die dermahligen aber dieses hoffs mit Eüer Kaÿserlichen Maÿestät, und Engelland anscheinende gute Freündschafft, gleich dem staub, verschwinden wurde: Ja Duras gienge so weit, daß Er zuvor dem Huescar,

[fol.38v] nachmahlens aber dem Wall die Frantzösische hülff wieder Engelland in gedachten Campeche, Tinto, und Muschitto anerbothe.

Keéne vnterließe nicht im Monath Maÿ seinen hoff von so gefährlichen Maaßnehmungen zu verständigen, und Neu Castle ruffte alsobald den spanischen bevollmächtigten $\mathrm{zu}$ sich, und machte demselben über eine so wichtige vorfallenheit die geziemende vorstellungen, Jhne ersuchend, einen Eigenen Courier deßenthalben an Seinen hoff absenden zu wollen. Der Courier Langte eben den donnerßtag, so den großen fall vorgegangen ist, in Madrid an. Beÿde Catholische Maÿestäten wurden darüber vngemein betroffen, und gleichwie der in Londen stehende spanische bevollmächtigte dem Enzenada eine abschrifft von seiner Depeche zugeschicket hatte, so erwartteten höchst Selbe, das Enzenada etwas davon melden solte, um doch zu sehen, mit was farben eine so häßlich= und aufrührische vnternehmung von ihme angestrichen werden wurde. Allein Enzenada hielte sich still. Der König, vnd Königin faßten darüber einen so großen vnwillen, daß Sie nicht Länger den vmsturtz dieses gefährlichen Manns verzögeren zu sollen glaubten: Schickten zugleich gemäßene befehle ohne verzug ab, um gemelte zu anzündung eines neüen Kriegsfeürs gerichtete Enzenadische Anstalten zu entkräfften.

35. König Philipp II von Spanien (1527-1598). Sein Name erscheint hier mit der lateinischen Dativendung auf -o. 
[fol.39r] Die feindseeligkeiten dörfften indesßen zwar angegangen, doch werden sie ohne weitere folgen seÿn.

Gleichwie, da man eine schlange in theile machet, die von dem haubt abgesönderte stücke sich noch einige zeit darauf zu rühren pflegen, also haben auch des Enzenada Lieblinge, und Anhängere nach dem fall ihres haubts sich vnterschiedliche bewegungen gegeben. Sie kunnten ohnmöglich begreiffen, daß desßen absetzung mit vorwisßen der Königin geschehen seÿe, weil ihnen nicht wahrscheinlich vorkame, daß höchst Selbe dem Farinello ein geheimnus darauß gemacht haben wurden. Dieser ware in dem nemmlichen irrwahn, und Folglich schmeichelten sie sich sammtlich, durch Seine Maÿestät die Königin des Königs vnwillen zubesänfftigen, und dem Huescar, und Wall andurch ein übles spiel zu machen. Allein seÿnd vielmehr beÿde Königliche Mä̈estäten über dero entschlüßung ungemein vergnügt, und nach Maaß, daß man schier alltäglich neüe schädliche räncke des Enzenada entdecket, wachset höchst dero wohlgefallen über die vollziehung eines so schönen Wercks immerfort an. Der Königin Frau Mutter hatte sich durch Caravalho verleiten Laßen, dero Frau tochter einen kleinen vorwurff zu machen, das höchsts Selbe den Huescar zu sehr zu erheben, und den Enzenada andurch zu verlaßen schienen. Seine Maÿestät aber

[fol.39v] erklärten in der antworth diesen Mann, alß einen feind Eüer Kaÿserlichen Maÿestät, und des allerdurchläuchtigsten Ertz-haußes, und mit deme Lehneten höchst Selbe die angeworffene beschuldigung von Sich ab.

Beÿ verhafftnehnung ${ }^{36}$ des Enzenada wurde alle schärffe, und Feÿerligkeit gebraucht, damit die Welt darauß ermeßen solte, daß Er höchst wichtiger, und Großer verbrechen sich schuldig gemacht habe: Gleichwie man aber die wahre staatts-vrsachen nicht an tag geben will, so ist man mit ihm, in dem weiteren fortgang seines verhaffts, alß mit einem einer sehr üblen, und sträfflichen Ambts verwaltung schuldigen Mann vmgegangen. Die Königin versaumet keine gelegenheit, dem König den glücklichen vnterschied, welcher zwischen des Enzenada, und derenjenigen, so nunmehro seine ämbter bekleÿden, betrag sich äußeret, in vollem Licht einsehen zu machen.

Farinelli ist ob seines freünds vnglück sehr betroffen: Allein alß beÿde Maÿestäten ihm den nemmlichen tag Gnädigst zu erkennen gaben, daß höchst deroselben, beÿ nehmung solcher entschlüßung, die betrachtung des Lebhafftesten Schmertzens, so Er Farinelli darüber fühlen wurde, nicht gleichgültig gewesen seÿn, so ist von ihm mit vieler vernunfft darauf erwiederet worden, daß, da einmahl ein so gerechter König den Enzenada verdammet hätte, er solchen

[fol. 4or] nicht mehr alß vnschuldig ansehen kunnte: Ja Er Farinello wurde selbst der erste gewesen seÿn, in seinem Freünd, beÿ ermanglung eines anderen, die über Jhn ergangene bestraffung außzuüben. Es wäre allerdings zu wünschen gewesen, daß Er immer in der nemmlichen sprach verblieben

36. «Verhaftnehmung», also «Verhaftung». 
wäre; Allein sein gutes Gemüth, und des Enzenada anhängere haben ihn zu einigen gefunden hätte, Er sich selbst nicht geringen schaden zugefügt haben wurde. Jch schmeichle mir, daß Er mich auch, beÿ dieser gelegenheit, nicht gäntzlich vnnutz, und ihme wahrhafft zugethann geprüfet habe.

Noch vor endigung dieses allerunterthänigsten berichtes, habe in sichere erfahrung gebracht, wie auß denen beÿ Enzenada gefundenen Schrifften erhelle, das Er eigenmächtig, und ohne vorwisßen des Königs, der verwittweten Königin zu S. Ildefonso zweÿ Millionen Pesos dargeliehen habe. Auf gleiche Art hat Er auch eine Leinwath-Factorie in Schlesien gekauffet, und denen handelß-Leüthen ein ziemliches stuck Gelds vorgestrecket, damit sie ihr gewerb treiben, und gedachte Leinwath, anhero Liefferen solten, glaublich in der absicht, die von Caravajal in Leon errichtete Leinwath-Fabric zu boden zu werffen. Alß der König von

[fol. 4ov] diesen Enzenadischen vnternehmungen verständiget worden, wurden Seine Maÿestät darüber so vngehalten, das Sie ihren vnwillen sogar mit stampfung deren füßen zu erkennen gaben.

Vor einigen wochen, alß des Duc d'Huescar Sohn von denen blattern gähling überfallen worden, und dahero sein herr vatter, welcher sich eben dazumahl beÿ dem krancken befande, durch die gewöhnliche vierzig täge vom hoff sich entfernet halten muß, so haben die lesuiten in dem Noviziat, glaubwürdigen auskunfften nach, einige zusamenkunfften gehalten, um zu berath schlagen, wie man sich die abweesenheit des Duc zu nutzen machen kunnte: Allein seÿnd andererseits die Maaßnehmungen so gut ergriffen worden, das falls der beichtvatter einen schritt wagen solte, ihme zur Antworth seine entlasßung zu theil werden dörffte, und ist wahrscheinlich, das Er sich um so mehr in acht nehmen, und ieden verfänglichen schritt sorgfältig vermeiden werde, weilen, da einmahl dieses wichtige Ambt von der Societät hinweck kommen solte, es so leicht nicht mehr zuruckkehren wurde. Eüer Kaÿserlichen und Königlichen Maÿestät empfehle mich allerunterthänigst zu beharrlichen Allerhöchsten hulden, und Gnaden, und geharre in tieffester Ehrfucht, und Erniedrigung.

Eüer Kaÿserlichen und Königlichen Maÿestät

Madrid, den I9.ten August. I754. allerunterthanigster treu gehorsamster Coadjutor v. Mechlen manu propria ${ }^{38}$

37. Migazzi ersetzte hier «vnterredungen» durch «reden».

38. Mit eigener Hand geschrieben. 


\section{TRADUCCIÓN DE LA FUENTE: LA RELACIÓN ESCRITA POR EL CONDE CHRISTOPH MIGAZZI A MARÍA TERESA, MADRID, 19 DE AGOSTO DE 1754}

[f. 29 r.] Augustísima y Poderosísima Emperatriz Romana, y también Reina Gobernadora de Hungría y de Bohemia

¡Clementísima Emperatriz, Reina y Señora Señora! ${ }^{39}$

Si el resultado de los asuntos fuera suficiente para justificar la parte que he tenido en ellos, no en vano me halagaría que el derrocamiento del marqués de la Ensenada hablara por los pasos que yo he dado en este asunto; sin embargo, Vuestra Majestad Imperial sabiamente no suele juzgar, según el juicio de la casi general mayoría de la gente, del éxito afortunado o desafortunado de una empresa, sino de la forma en que dicha empresa ha sido perseguida

[f. 29 v.] por lo que Vuestra Alteza me digna permitir, apartarme en este momento un poco de la intención que me había hecho respecto a mí mismo, que es, o bien no hablar nada o bien de la manera más breve y limitada posible, y recuperar el asunto desde su origen, para recaer posteriormente en aquello que me movió y empoderó a entregar el pliego presente.

Ya en la época del difunto Carvajal, yo tenía conocimiento fehaciente de que la reina gobernadora había reducido la gran confianza que antes depositaba en Ensenada, y había empezado a desconfiar de su comportamiento y se había pasado al bando de Carvajal. Pero como este ministro, en parte por desprecio a Ensenada, en parte por su aferrada pusilanimidad, nunca se ha esforzado contra él con seriedad y firmeza, así las cosas, entre los dos quedaron tan equilibradas que uno no pudo bien ganar la partida al otro. Además, recibí ciertas informaciones de que la reina había amonestado varias veces al citado Carvajal para que se empeñara de conseguir algunas pruebas firmes de las acusaciones lanzadas contra Ensenada, para luego poder proceder con justa causa contra este. Pero Carvajal al mismo

[f. $30 \mathrm{r}$ ] tiempo, en el que se quejaba incesantemente del mal estado de las cosas, lo tomó como cuestión de conciencia y en contra de su nacimiento, o bien hacer hablar a un tercero y subordinado de Ensenada, o bien abrir las frecuentes cartas que llegaron a Ensenada. Poco antes de su muerte, se liberó de esta temerosidad de la conciencia, que le había llevado demasiado en su puesto, y no le fue difícil conseguir muchas, e importantes, escrituras que hablaron en contra de Ensenada; por una inesperada coincidencia también pudo apoderarse de tales cartas, que mostraban claramente que el confesor no tuvo poca participación en la rebeldía

39. María Teresa era «rex Hungriae», es decir, se usó el título masculino, ya que la expresión femenina «regina» habría implicado que ella era la consorte del rey. Al parecer, Migazzi expresa este concepto aquí con el término «regierende Königin (reina gobernadora)». Además, como María Teresa rehusó participar oficialmente en la coronación imperial romana de su esposo Franz / Francisco I en 1745, legalmente era consorte imperial. No obstante, los vasallos sabían que ella era la heredera de los territorios de Habsburgo y por lo cual, Migazzi se dirigió a ella como la «Kaiserin (emperatriz)», véase STOLLBERG-RILINGER, 2017: 89, 95, 106-109, 127. 
mostrada por los indios contra los ingenieros españoles y portugueses que fueron enviados para determinar las fronteras, en que el confesor animaba a los misioneros que residieron con esos pueblos a no obedecer las órdenes de las dos Coronas, como de hecho los indios mencionados expulsaron a los comisarios españoles y portugueses, y declaraban libremente que no debían obediencia a nadie más que a esos patribus Societatis Jesu $\mathrm{u}^{40}$. Un sobrino de Don Facondo ${ }^{41}$ se dejó utilizar como negociador y transmisor de dichas cartas,

[f. 30 v.] y Ensenada estuvo de acuerdo con el confesor en todo este desorden. Ahora que Carvajal ha despertado de su letargia, y ha hecho los más bellos preparativos, primero para informar a la reina, y después, con su permiso, al Rey de tan peligrosas y feas conspiraciones, se ve vencido por el inesperado sueño de la muerte, que le ha cerrado constantemente los ojos y la boca. Pero hablaron sus escritos, que él dejó, y en los que todo fue registrado exactamente por él, y su opinión sobre el mismo fue claramente revelado al Rey. Al igual que su indisposición se mostró muy peligrosa desde el principio, y también le arrancó de este mundo en el corto espacio de tres días, se celebraron muchas reuniones secretas en la casa de Ensenada, y en las mismas se llegó a la conclusión de que él se mantuviera callado y quieto, pero que sus seguidores hicieran todo lo posible para procurarle el puesto que tenía prisa por ocupar. Duras ${ }^{42}$ era informado de todo, y también no se abstuvo de hacer cualquier cosa que pudiera favorecer la propuesta que se había hecho. Yo, en cambio, había tenido la suerte de encontrar un medio decente para solicitar adecuadamente a la reina gobernadora de acordarse de Vuestra Majestad Imperial en una ocasión tan importante como delicada. Y efectivamente, el domingo

[f. 3I r.] por la noche en la antecámara del moribundo Carvajal se me aseguraron en el nombre de la reina que nadie entraría en la administración de los negocios extranjeros que pudiera ser sospechoso a Vuestra Majestad Imperial. Lo que siga ocurriendo en este caso se digna Vuestra Majestad Imperial observar de mis más humildes informes que entregué al Correo Prennschitz. ${ }^{43}$ Ensenada, Duras y sus seguidores se vieron muy afectados por el interino del duque de Huéscar; pero se recuperaron en poco tiempo, y redoblaron sus esfuerzos para apartar a dicho duque de sus negocios para siempre. Cómo convencer a la reina de tan perjudicial juicio, cómo el confesor ha procurado perseguir las mismas intenciones de Ensenada, y buscó de servirse de la ternura de conciencia del Rey, es también conocido por Vuestra Majestad Imperial.

Si hubiera seguido según el primer impulso y celo del Rey Católico, tanto Ensenada como el confesor habrían cortado su esperanza de inmediato, y ambos se habrían visto fuera de sus puestos. Hubiera sido muy fácil para el Rey tomar tal decisión, porque

40. Padres de la Sociedad de Jesús, es decir, los jesuitas.

41. El abate Facundo Mogrovejo (finales del siglo XVII-1757), confidente de Ensenada.

42. El embajador francés, Emmanuel-Félicité de Durfort, duque de Duras (en Madrid 1752-55).

43. El correo de la corte, Lorenz Prenschitz. 
por una parte empezaron a serle pesado y sensible el carácter dominante del confesor, y el yugo impuesto por él, y por otra parte Ensenada, a quien Su Majestad nunca

[f. 3I v.] tuvo afecto de todos modos y su conducta y administración le comenzaron a ser sospechosos. A tal estado de cosas se difundió generalmente la noticia del nombramiento de Wall, y por ello el mencionado Ensenada y el confesor juntos con todo el partido francés tomaron ocasión para esforzarse muy diligentemente con ambas Majestades contra Huéscar. Sin embargo, ningún medio era suficiente para que el Rey enfriara su ternura hacia Huéscar. Tampoco se podía inducir a la Reina a que devolviera su antigua confianza y gracia a Ensenada, pero se la pondría en un aprieto haciéndole comprender cómo Huéscar no iba a estar mucho tiempo junto al Rey sin ganar la partida a todos; incluso una vez que el contrapeso se perdiera, Su Majestad podría convertirse en la primera víctima de su desmesurada prepotencia. Por otro lado Wall, aún sin la ayuda de Huéscar, sería capaz de mantener a Ensenada en los límites adecuados, y al mismo tiempo tendría que seguir siempre dedicado al servicio de $\mathrm{Su}$ Majestad la Reina, porque sin su protección no podría mantenerse a largo plazo. De lo cual fluyó otra consecuencia, que con un poder tan dividido, y contendiendo con fuerzas iguales entre sí, Su Majestad la Reina mantendría siempre la balanza en sus manos, junto con la libertad de dirigirla según su propio placer y arbitrio.

[f. 32 r.] Huéscar, en contra, había tomado la decisión de o apartarse de la corte o de ver a Ensenada derrocado. Esta resolución era un tanto más fácil de tomar para él, ya que tenía gran confianza en la amistad de Wall. Farinelli ${ }^{44}$, en su lugar, estaba igualmente constantemente en los oídos de la Reina a favor de la Ensenada, y era prueba fehaciente para mí de que precisamente esta amistad ciega con su mencionado ministre fue la verdadera causa, por la cual sus Majestades mismos hicieron un secreto a Farinelli de todo lo que sucedió después de la muerte de Carvajal.

Esta inquietud y duda, suscitadas en el ánimo de la Reina por tan intrincadas circunstancias, la indujeron a preguntarme ¿qué pensaba realmente de la elección de Wall? La cuestión no era seca, sino que se basaba en las circunstancias que se habían tocado en primer lugar, y se exigía mi opinión según la medida de las mismas. ¿Si Wall, sin el Duque de Huéscar, tendría fuerza suficiente para detener a Ensenada, que, como un río vasto estaba arrasando todo a su alrededor? Por lo tanto, creí que no hubiera cumplido con mi deber

[f. 32 v.] si no hubiera sido claro y tajante en una ocasión tan importante -y decisiva para el bienestar del más alto servicio. También me correspondería, al menos hasta donde alcanza la cautela y la prudencia humanas, no temer lo más mínimo. De la honesta y noble disposición de la Reina, de su sigilo hacia Farinelli, y su incrementada sospecha hacia Ensenada que ya se había despertado en los últimos tiempos de Carvajal, pero que aumentó considerablemente después de su muerte, podía yo considerarme completamente convencido, y no hubiera sido la primera vez que la

44. El cantante Carlo Broschi, conocido como Farinelli, amigo de Ensenada y confidente de la reina. 
Reina me mostraba la mayor gracia, para dejar solicitar mi humilde opinión en sus propios asuntos. Sin embargo, he considerado mantenerla encerrada conmigo mismo por la honradez, la conciencia y por el servicio de Vuestra Majestad Imperial. Hay que constar, igraciosísima Señora! el verdadero curso del asunto. No obstante, Vuestra Majestad Imperial tengan la bondad de apartar, aunque sea por un solo momento, su más viva imaginación de la mencionada confluencia de tan extrañas circunstancias, y meramente constar con la más esclarecida percepción que las dos partes adversas lucharon tan vivamente entre sí,

[f. 33 r.] que ya no sería posible prolongar el equilibrio entre su existencia, sino que necesariamente uno de los dos tendría que hacer de amo. Uno de ellos, por decirlo de alguna manera, iría a por la vida del otro, pero con la diferencia de que Ensenada se habría contentado con preservarse mediante artimañas e intrigas secretas, para desgastar al Huéscar, y poder finalmente llevarlo a esa decisión que el duque había tomado de verdad en el pasado, de abandonar la corte en caso de un resultado adverso de sus asuntos. Wall se habría visto después en la necesidad de inclinarse ante Ensenada o, lo que habría sido más probable, de seguir a su patrón y amigo, el Huéscar. Si, una vez dispersados los bienintencionados españoles, el partido francés se hubiera apoderado de todo el poder y la autoridad, se habrían revelado a todos las consecuencias más perniciosas, que habrían originado para la tranquilidad general de Europa y para el bienestar de los negocios de Vuestra Majestad Imperial, que está tan estrechamente relacionado con ella y de la mayor desventaja para la propia España. El asunto no admitía ningún remedio. Ensenada no podía estar al lado de Huéscar y sus seguidores, y Huéscar quería estar al lado de Ensenada, que significa tanto que había llegado el decisivo

[f. 33 v.] momento de las cosas más importantes, ya sea para ver a España nuevamente hundida bajo el yugo francés, o para levantada en su dignidad y libertad. No se trataba de que los asuntos de guerra y el mar, los tesoros de las Indias y de España quedaran en manos de Ensenada o de un tercero. Tal cosa me hubiera sido indiferente; pero lo que importaba era que este reino, que tanto contribuye a la tranquilidad de Europa, corriera el riesgo evidente de convertirse en un instrumento seguro de las tan malignas intenciones de la Corte francesa.

Para tan peligrosa crisis, aunque no hubiera tenido las anteriores seguridades indicadas por mí en cuanto al secreto de mis pasos, aún me habría expuesto al propio reproche de mi conciencia, si no me hubiera servido de aquellas medidas, que la divina prudencia no parecía querer darme en vano para el rechazo de tan tremenda tormenta. La indiferencia entre los dos partidos por el servicio de Vuestra Majestad Imperial no habría podido ganar a Ensenada, sin embargo, habría muy ciertamente perdido el Huéscar y Wall; y entonces el gran amor y la sincera amistad

[f. 34 r.] de la Reina gobernadora no hubieran sido accesibles por Vuestra Majestad Imperial para mantener el actual buen entendimiento de ambas altísimas cortes, si Ensenada hubiera mantenido el campo. Pero si Vuestra Majestad Imperial permitiera el peor de los casos, que el mismo Ensenada hubiera ganado realmente la partida 
a los bienintencionados. Entonces, según mi ligera discreción, tal empresa habría sido llevada a cabo por mí; de lo cual el beneficio podría recaer en Vuestra Majestad Imperial, el daño, en cambio, sólo en mí. Yo hubiera sido el primero que me hubiera acusado ante Vuestra Majestad Imperial, y al mismo tiempo hubiera declarado que, después de que el destino adverso de España hubiera entregado el reino en manos de sus mayores enemigos, mi permanencia en el servicio de Vuestra Majestad Imperial ya no podría ser más provechosa, ya que no habría que esperar ni confianza, ni benevolencia de los que llevan el timonel. Vuestra Majestad Imperial, sin embargo, habría demostrado claramente con mi despido que desaprueba de mi conducta, y con ello toda la culpa recaería en mí solo en la vista de todos.

[f. 34 v.] Vuestra Majestad Imperial se complacerá en recordar de manera clementísima que, dado que, a mi regreso de Roma, algunos en Viena me dieron a entender que la coadjutoría de Malinas, que me había sido graciosamente asignada, podría causar alguna desventaja al más alto servicio en los Países Bajos, me he ofrecido inmediatamente a renunciar a ella a los pies de Vuestra Majestad Imperial. Cuando ahora un sustento perpetuo, en consideración al servicio de Vuestra Majestad Imperial, se ha vuelto indiferente para mí, ¿debería haber dudado en exponerme al peligro de perder un empleo muy brillante, y muy por encima de mi capacidad, pero sólo temporal, para dar un paso, cuyo feliz éxito podría mejorar las cosas inmensamente, pero el adverso no podría empeorarlas ${ }^{45}$ ?

Paso por alto muchas otras circunstancias, que, aunque considerables, no son esenciales para el asunto del que se trata, y por lo tanto no me queda otra que, después de una confesión tan franca y sincera, someterme de forma más rendida al más esclarecido juicio de Vuestra Majestad Imperial sobre mi conducta.

[f. 35 r.] Vuestra Majestad Imperial se digna de considerar que aquí expongo de forma más rendida la verdadera causa que promovió el derrocamiento del Ensenada y las circunstancias secretas que las produjeron o acompañaron. Wall, al devolver el correo que le habían despachado a Londres, había dictado unas líneas de cortesía hacia Ensenada, pero al mismo tiempo había hecho saber de forma clara y extensa al duque de Huéscar que si su retirada de Londres tenía como objeto la Secretaría de Estado, no estaría dispuesto a aceptarla, y que su principal agravio era la potestad de Ensenada. Cuando el Rey se enteró de Huéscar tanto de las cartas de Wall a Ensenada como de la aversión al puesto que se le eligió, Su Majestad ordenó que se quemara la carta y, respecto a la segunda, ordenó al duque de Huéscar que secretamente enviara un correo para Wall a las fronteras de España, para que diera noticia a Alcalá el día de su llegada y visite preliminarmente a Huéscar, y, antes de su entrada en Aranjuez se informe de la

[f. 35 v.] opinión genuina del Rey.

45. Quiere decir, que Migazzi no dependía exclusivamente de sus ingresos de diplomático, sino que seguía teniendo la coadjutería y, por tanto, podía correr más riesgos en Madrid en pro de María Teresa. 
Wall, por lo tanto, en la primera entrevista con Huéscar, concluyó de inmediato que no deseaba servir al lado de Ensenada y Huéscar renovó su antigua resolución, ambos con la intención de librar a España de tan pernicioso hombre, devolverle [a España] el esplendor y el prestigio anterior que tanto habían disminuido por él. A partir de ese momento se afanaron para asegurar tales pruebas, por las que la Reina quedara irremediablemente convencida de la correspondencia secreta de Ensenada con Francia, Portugal, Nápoles ${ }^{46}$ y San Ildefonso ${ }^{47}$. Así como este hombre llegó al límite de su medios, él se dejó adormecer por una certeza demasiado grande, y así dio pie a que sus cartas y las de sus seguidores cayeran en manos de estos dos hombres alertas, valientes y hábiles. Después de que estos dos se vieron provistos y equipados de suficientes pruebas, se compuso por ellos un escrito, en el que se ponía claramente ante los ojos tanto la correspondencia secreta de Ensenada con las dichas cortes extranjeras como su perjudicial y la mala administración en el interior. La caída del poderío bélico, las inútiles empresas en los asuntos navales,

[f. 36 r.] el despilfarro de tantos millones y el dominio despótico en todas las cosas de este hombre vano constituyeron el tema de la última frase del escrito que se presentó. La Reina fue informada de este papel, y después de haber ordenado algunos cambios que se ajustaban a la forma de pensar del Rey, dio permiso a Huéscar y a Wall para que hicieran más uso de él con el Rey. Mucho se ganó con esto, pero la circunstancia principal dependía del confesor, que se puso completamente del lado de Ensenada y alabó siempre al Rey las excelentes cualidades y inestimables méritos de este hombre. Pero como Dios quiere llevar a cabo su obra, también da los medios adecuados a quienes deben ser los ejecutores e instrumentos de su voluntad. La conducta rebelde de los jesuitas indianos, el acuerdo secreto del confesor con ellos, y las demás confirmaciones recibidas de Huéscar y Wall en este asunto, les dieron material suficiente para que el Rey sospechara de su guía de conciencia. Como tan evidentemente había tomado partido por Ensenada, y se había unido tan estrechamente con Don Facondo, y varios otros

[f. 36 v.] de la misma servidumbre, fue herido por las mismas armas con las que pensaba infligir un golpe fatal a los demás. Por lo tanto, sólo era cuestión de elegir un momento conveniente para informar al Rey de tan importantes asuntos. En Aranjuez, Su Majestad estuvo este último tiempo sometido a algunos pequeños ataques de salud y a la melancolía, por lo que hubo que esperar el regreso a Madrid. La Reina, sin embargo, no perdió ninguna oportunidad de entretener en el corazón del Rey la ternura hacia Huéscar, y en su mente la alta estima ante Wall, por otra parte, dejó de entrever algún recelo a causa del confesor y de Ensenada.

Ensenada, aunque no podía dejar de darse cuenta de que la estrecha unión de Huéscar y Wall podía tener por objeto, entre otras cosas, su reducción, fue también

46. Se refiere al rey Carlos de Borbón en Nápoles y Sicilia (a partir de 1734 / 35), que a partir de 1759 se convirtió en Carlos III de España.

47. Es decir, la reina viuda Isabel Farnesio que residió en La Granja de San Ildefonso. 
amonestado por algunos de sus amigos para que se pusiera en guardia, sin embargo confiaba tanto en la habilidad del confesor, y de Farinelli, que estimó pequeños e infructuosos todos los esfuerzos adversos. Nunca se le ocurrió que las Majestades Católicas llegarían a una resolución considerable,

[f. 37 r.] sin que el Rey las discutiera por el momento con el confesor, y la Reina hablara de ellas a Farinelli.

Hacia la mitad del último mes se atrevió el ataque, y antes de que Huéscar y Wall comenzaran a revelar su plan al Rey, pidieron a ambas Majestades a guardar el secreto más íntimo y sagrado. El Rey les dio la palabra, relatando que había notado hace tiempo que pretendían presentar algo importante ante Él; pero debían estar asegurados de que Él no se preocuparía por ello, sino que sólo haría lo que era correcto y justo. Del confesor, pues, hicieron el principio, y procedieron de ellos a Ensenada; el asunto también fue tan feliz que en dos actuaciones se tomó la conclusión conocida. El Rey también quería deshacerse del confesor, pero no era posible proponer a nadie más inmediatamente, porque no se podía persuadir a aquellos en los que el Rey tenía confianza para que aceptaran este cargo. $\mathrm{Ni}$ Huéscar y Wall ya no se interesaron mucho más por el confesor, porque, como el Rey había albergado una desconfianza tan fundada contra él, que sus sugerencias

[f. 37 v.] no encontrarían fácilmente aceptación por Su Majestad. Y, en efecto, después de la caída de Ensenada, el confesor no se atrevió a hablar de ningún asunto con el Rey, mientras que Su Majestad se limitó a una mera confesión con él. Con todo esto no se debe mantener con el confesor por mucho tiempo. Una coincidencia inesperada pero muy importante puede haber promovido el derrocamiento de Ensenada. Vuestra Majestad Imperial sabrá muy bien cómo, entre los puntos aún no arreglados entre España e Inglaterra, el gran pantano de Campeche en las Indias es uno de sus mayores agravios, en la cual, en esta franja de tierra deshabitada y muy insalubre, se han establecido algunos ingleses y han comenzado a cortar la madera que es tan útil para teñir sus telas. Ya que, por otro lado, España quiere considerar esta empresa como una invasión de sus derechos. Hace ya dos años, se propuso un medio de arreglo por parte de Inglaterra, que los súbditos de las dos coronas establecieran una empresa para algunos años, y realizaran conjuntamente la tala de árboles hasta que se discutiera formalmente el asunto. Ensenada pareció aprobar esta propuesta y aseguró a Keene que se podían juntar sobre esto.

[f. 38 r.] Pero el asunto había sido deliberadamente pospuesto de un tiempo a otro, hasta que por fin Keene llegó a saber con ciencia que después de la llegada de Duras, Ensenada había caído en ideas totalmente diferentes, y se había aprobado una nueva propuesta hecha por un tercero, cuyo contenido era al efecto de que los ingleses debían ser expulsados por la fuerza de dicho Campeche, de la costa de 
Muschitto, y del río Tinto ${ }^{48}$. En efecto, hacía algunos meses que Ensenada había dado órdenes, en el mayor secreto, de que varios barcos zarparan de distintos puertos españoles, se unieran a cierta distancia de Muschito y se abalanzaran hostilmente sobre los ingleses. Una vez iniciadas las hostilidades, Ensenada habría echado toda la culpa a Inglaterra, y arrojado al Rey Católico contra su voluntad en manos de los franceses.

Duras, y sus seguidores, fueron tan despreocupados, que se dejaron oír, cómo la paz con Inglaterra duraría unos meses más, y en consecuencia se establece la unión entre España y Francia, tal y como se había hecho bajo el Rey Felipe ${ }^{49}$, que en paz descanse, y la aparente buena amistad que esta corte tenía con Vuestra Majestad Imperial e Inglaterra desaparecería como el polvo. Es más, Duras llegó a tal extremo, que ofreció primero al Huéscar,

[f. 38 v.] y luego al Wall, la ayuda francesa contra Inglaterra en dicho Campeche, Tinto, y Muschitto.

Keene $^{50}$ no se abstuvo en el mes de mayo de informar a su corte de tan peligrosas providencias, y Newcastle citó inmediatamente al plenipotenciario español, y le hizo las debidas presentaciones sobre tan importante incidente, pidiéndole que quisiera enviar un mensajero suyo a su corte para este fin. El mensajero llegó a Madrid justo el jueves precedente de la gran caída. Ambas Majestades Católicas estaban inmensamente afectadas por esto, y así como el plenipotenciario español en Londres había enviado a Ensenada una copia de su despacho, y sus Majestades esperaban que Ensenada informara algo al respecto, para ver con qué colores sería pintada por él una empresa tan fea y revoltosa. Pero Ensenada se mantuvo en silencio. El Rey y la Reina estaban tan disgustados por esto que pensaron que no debían retrasar más el derrocamiento de este peligroso hombre. Al mismo tiempo, enviaron sin demora las órdenes apropiadas, con el fin de invalidar cualquier esfuerzo Enzenadista destinado a encender un nuevo fuego de guerra.

[f. 39 r.] Las hostilidades pueden haber comenzado mientras tanto, pero no tendrán más consecuencias.

$\mathrm{Al}$ igual que, cuando se corta una serpiente en pedazos, los trozos separados de la cabeza aún tienden a agitarse durante algún tiempo, también los queridos y seguidores de Ensenada se han dado diferentes movimientos tras la caída de su cabeza. No podían entender que su deposición hubiera ocurrido con el conocimiento previo de la Reina, porque no les parecía probable que la Reina se lo hubiera ocultado a Farinelli. Este último estaba en la misma ilusión, y en consecuencia todos se lisonjeaban de apaciguar el disgusto del Rey por medio de Su Majestad la Reina, y de hacer un mal juego a Huéscar y a Wall. Sin embargo, ambas Majestades Reales están mucho más satisfechas con esta decisión, y tras el hecho de que casi todos los

48. Es decir, la Mosquitía / costa de los Mosquitos. En italiano la «ch» antes de «i» hoy suele pronunciarse como «qu / k». El río Tinto se ubica en Honduras.

49. El rey Felipe II (1527-1598).

50. Embajador británico Benjamin Keene. 
días se descubren nuevas nefastas intrigas de Ensenada, su placer por la ejecución de tan bella obra sigue creciendo. La señora madre de la Reina se había dejado seducir por Caravalho ${ }^{5 \mathrm{I}}$ de hacer un pequeño reproche a su hija por parecer levantar demasiado al Huéscar y dejar a Ensenada. Su Majestad, sin embargo,

[f. 39 v.] en respuesta, declaró a este hombre por un enemigo de Vuestra Majestad Imperial y de la Augustísima Casa, y con ellos rechazó la acusación.

Durante la detención de Ensenada, se empleó toda la gravedad y solemnidad, para que el mundo realizara que había sido culpable de los más importantes y grandes delitos. Sin embargo, como no se quiere revelar las verdaderas causas del Estado, se le trató, en el curso posterior de su detención, como un hombre culpable de una muy mala y criminal administración. La Reina no pierde ninguna oportunidad de hacer que el Rey vea en plena luz la feliz diferencia entre Ensenada y los que ahora ocupan sus cargos. Farinelli está muy afectado por la desgracia de su amigo. No obstante, cuando ambas Majestades le informaron benignamente el mismo día que ellos, al tomar tal decisión, no eran indiferentes a la consideración del más vivo dolor que Farinelli sentiría por ello, replicó con mucha razón que, puesto que un Rey tan justo había condenado ahora a Ensenada,

[f. 40 r.] ya no podía considerarlo inocente. Sí, Farinelli el mismo habría sido el primero, en ausencia de otro, en ejecutar en su amigo el castigo que se le infligió. Hubiera sido deseable, sin embargo, que hubiera permanecido siempre en el mismo lenguaje; su buen temperamento, y los seguidores de Ensenada le han animado a hacer algunos discurso ${ }^{52}$, con los que, si no hubiera encontrado buenos amigos, se habría hecho no poco daño. Me halaga que incluso en esta ocasión me haya puesto a prueba de forma no completamente inútil y verdaderamente entregada a él.

Antes de terminar este más rendido informe, aprendí con certeza como las escrituras encontradas con Ensenada esclarecen que él ha prestado por propia cuenta y sin conocimiento previo del Rey, dos millones de pesos a la Reina viuda en San Ildefonso. Asimismo, ha comprado una fábrica de lino en Silesia, y ha adelantado un trozo notable de dinero a los comerciantes para que aquí hagan su comercio y entreguen el mencionado lino, presumiblemente con la intención de destruir la fábrica de lino establecida por Caravajal en León ${ }^{53}$. Cuando el Rey

[f. 40 v.] fue informado de estas empresas Ensenadistas, Su Majestad se disgustó tanto que incluso mostró su descontento dando pisotones.

Hace unas semanas, cuando el hijo del duque de Huéscar fue atacado repentinamente por la viruela y, por tanto, su padre, que se encontraba con el enfermo, de Austria.

51. Sebastião José de Carvalho e Melo era primer ministro de Portugal, y la madre era la reina María Ana

52. En este caso, Migazzi tachó el prefijo y el sufijo para dar otro significado a la palabra.

53. Se refiere a la Real Fábrica de Lienzos de León, que, según HeLGUERA QuIJADA, 2017, 222-223, empezó a operar en 1751 con tejedores neerlandeses pero que decayó después de la muerte de Carvajal y Lancaster y en 1769 era abandonada. 
tuvo que ausentarse de la corte durante los cuarenta días habituales, los jesuitas, según informaciones creíbles, celebraron algunas reuniones en el noviciado para discutir cómo aprovechar la ausencia del duque. Por otro lado, se han tomado las medidas tan bien que si el confesor se atreviera a dar un paso, probablemente sería despedido en respuesta, y es probable que tenga aún más cuidado y evite cuidadosamente cualquier paso embarazoso, porque si este importante cargo se alejara una vez de la Sociedad, no volvería tan fácilmente.

Vuestra Majestad Imperial y Real me encomiendo muy rendidamente a los más altos y perseverantes favores y gracias, y me encuentro en la más profunda reverencia y humillación.

Vuestra Majestad Imperial y Real.

Madrid, el i9 de agosto de I754 Vuestro más rendido y fielmente obediente coadjutor de Malinas, con su propia mano 


\section{BIBLIOGRAFÍA}

ARneth, Alfred Ritter von, Maria Theresia nach dem Erbfolgekriege I748-I756, en Geschichte Maria Theresia's, Viena, Wilhelm Braumüller, ı870. Vol. 4.

Baudot Monroy, María, La defensa del Imperio. Julián de Arriaga en la Armada (I7ooI754), Ministerio de Defensa / Cátedra de Historia Naval de la Universidad de Murcia, Madrid, 20I3.

Edelmayer, Friedrich, León Sanz, Virginia \& Ruiz Rodríguez, José Ignacio (eds.), Hispania-Austria III: Der Spanische Erbfolgekrieg. La Guerra de Sucesión española. Viena, Verlag für Geschichte und Politik / Munich, Oldenbourg, 2008.

Gómez Urdañez, José Luis, Fernando VI, Madrid, Arlanza, 20oI.

Helguera Quijada, Juan, «Un empeño fallido de reindustrialicazión: las reales fábricas del siglo XVIII en Castilla y León», en Francisco Comín Comín, Ricardo Hernández García y Javier Moreno Lázaro (eds.), Instituciones políticas, comportamientos sociales y atraso económico en España (1580-2000): Homenaje a Ángel García Sanz, Salamanca, Ediciones Universidad de Salamanca, 20I7, 2II-246.

Hersche, Peter, «Migazzi, Christoph Graf», en Neue Deutsche Biographie [En línea] I7 (I994): 486-488. Consultado el I7 de Mayo de 202I. URL: https://www.deutschebiographie.de

JuRETSCHKe, Hans (ed.), Berichte der diplomatischen Vertreter des Wiener Hofes aus Spanien in der Regierungszeit Karls III. I759-I788 / Despachos de los representantes diplomáticos de la Corte de Viena, acreditados en Madrid durante el reinado de Carlos III. Madrid: GörresGesellschaft / Consejo Superior de Investigacion Cientifica, I970.

Kuethe, Allan J. \& Andrien, J. Kenneth, The Spanish Atlantic World in the Eighteenth Century: War and the Bourbon Reforms, I713-I796, Cambridge, Cambridge University Press, 2014.

LyNCH, John, Bourbon Spain, I700-I808, Oxford, Basil Blackwell, I989.

Lodge, Richard (ed.), The Private Correspondence of sir Benjamin Keene, K. B., Cambridge, Cambridge University Press. I933.

Molina Cortón, Juan, Reformismo y neutralidad. José de Carvajal y la diplomacia de la España preilustrada, Mérida, Editorial Regional de Extremadura, 2003.

Ozanam, Didier (ed.), La diplomacia de Fernando VI. Correspondencia reservada entre D. José Carvajal y el Duque de Huescar, I746-I749, Madrid, C.S.I.C., Escuela de Historia Moderna, I975.

Stein, Stanley J. \& Stein, Barbara H., Silver, Trade, and War. Spain and America in the Making of Early Modern Europe, Baltimore y Londres, Johns Hopkins Press, 2000.

Stollberg-Rilinger, Barbara, Maria Theresia. Die Kaiserin in ihrer Zeit, Munich, C. H. Beck, 2017.

TÉllez Alarcía, Diego, «El Caballero Don Ricardo Wall y la conspiración antiensenadista», en José Miguel Delgado Barrado y José Luis Gómez Urdáñez (eds.), Ministros de Fernando VI, Córdoba, Servicio de Publicaciones, Universidad de Córdoba, 2002, 95-I38.

Téllez Alarcía, Diego, D. Ricardo Wall. Aut Caesar aut nullus, Madrid, Ministerio de Defensa, 2008.

TÉllez Alarcía, Diego, El ministerio Wall: la «España discreta» del «ministro olvidado», Madrid, Marcial Pons Historia, 2012. 
WhALEY, Joachim, Germany and the Holy Roman Empire: Volume I: Maximilian I to the Peace of Westphalia, I493-I648, Oxford, Oxford University Press, 201 .

Wolsgruber, Cölestin, Christoph Anton Kardinal Migazzi: Fürsterzbischof von Wien, Saulgau, Hermann Kitz, I890. 


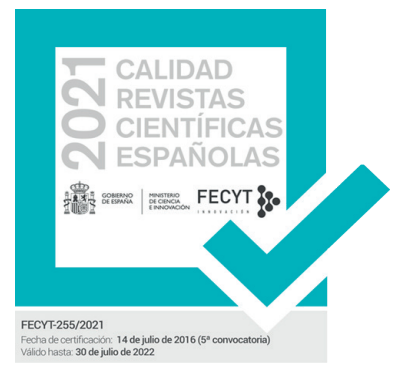

SERIE IV HISTORIA MODERNA

REVISTA DE LA FACULTAD DE GEOGRAFÍA E HISTORIA

AÑO 2021

ISSN: 1131-768X

E-ISSN 2340-1400

\section{4 \\ 西 ESPACIO, TIEMPO Y FORMA}

Monográfico - Special Issue: La política ultramarina de las monarquías ibéricas (circa 1700-1750): una historia de fracasos y éxitos relativos The Overseas Policy of the Iberian Monarchies (Circa 1700-1750): A History of Failures and Relative Successes

15 Roberto Quirós Rosado y MARIA FERnANDA BICALHO La política ultramarina de las monarquías ibéricas (circa 1700-1750): una historia de fracasos y éxitos relativos / The Overseas Policy of the Iberian Monarchies (Circa 1700-1750): A History of Failures and Relative Successes

\section{Guillaume Hanotin}

Defender negocios en tiempo de convulsión política: las elites mercantiles francesas durante la guerra de Sucesión española / Protecting Business in Time of Crisis: French Trademen during the War of Spanish Succession

\subsection{Maria Fernanda Bicalmo}

Ultramarino y el auge de los secretarios de Estado en Portugal durante la primera mitad del siglo XVIII / Sobre este modo de resolver e despachar os negócios. The decline of the Overseas Council and the Rise of the Secretaries of State in Portugal during the First Half of the $18^{\text {th }}$ Century

\section{9}

\section{VALENTINA FAVARò}

El fracaso de los proyectos de reforma en el virreinato peruano de principios

del siglo XVIII. Las propuestas de Carmine Nicola Caracciolo, príncipe de Santobuono the Eighteenth Century. The Proposals of Carmine Nicola Caracciolo, Prince of Santobuono

\section{7}

\section{ROBERTO QUIRÓS ROSADO}

Ecos de un mercantilismo truncado. El conde de Pinos Puente y la diplomacia comercial de Carlos VI en la corte de Lisboa (1723-1724) / Echoes of a Failed Mercantilism. The Count of Pinos Puente and the Commercial Diplomacy of Charles VI at the Court Of Lisbon (1723-1724)

\section{Junia Ferreira Furtado}

Portuguese America under Foreign Threat and the Creation of the Concept of uti possidetis in the First Half of the $18^{\text {th }}$ Century / La américa portuguesa bajo la amenaza exterior y la creación del concepto de uti possidetis en la primera mitad del siglo XVIII

\section{Miscelánea $\cdot$ Miscellany}

\section{JosÉ Antonio Mateos Royo}

con Cataluña / Trade Policy and Monetary Circulation in Aragon: Conflicts and Agreements with Catalonia (1535-1565)

\section{Fernando Altoé}

panegíricos atribuidos a la impresion. Un estudio de la trayectoria de dos the Trajectory of Two Panegyrics Attributed to João de Barros

\section{Francisco Velasco Hernández}

reino de Murcia (siglos XVI y XVII) / The Influence of the Berber Corsican on the Late Repopulation on the Coastal Area on the Kingdom of Murcia (XVI and XVII Centuries)

\section{José Antonio Martínez Martínez}

Criados, jornaleros y esclavos al servicio de la familia: la servidumbre de Serfdom of the Muñoz de Otálora in the $17^{\text {th }}$ Century

\section{Víctor Daniel Regalado González-Serna}

Benito de Medina a raíz de su ingreso en el cabildo catedral de Sevilla en 1669 / «Not a Single Good Portuguese». Accusations against Priest Alonso Benito de Medina when Entering the Cathedral Chapter of Seville in 1669

\section{José Herrera Reviriego}

organigrama comercial y militar de la Gober mitad del siglo XVII / "Only Time will Tell us»: The Role of Taiwan within the Commercial and Military Organization of the Philippine's Governoration during the First Half of the Seventeenth Century

\section{Manuel-Reyes García Hurtado}

de Rande, 1719-1733 / Vicissitudes of the Rescue Companies of the Sunken Ships in the Battle of Rande, 1719-1733

\subsection{Marcos de Miguel MuÑoz}

Caballeros in 1769 


\section{4 ESPACIO, TIEMPO Y FORMA}

\section{Javier Tinoco Domínguez}

Tensiones sociopolíticas en el marco del catastro de Fnsenada en Jerez de la Frontera: estudio de un conflicto institucional / Socio-Political Tensions within the Framework of Cadastre of Ensenada In Jerez de la Frontera: A Studying of an Institucional Conflict

\section{Pablo Fernández Albaladejo}

Fábulas de origen y gramática de nación en la España del siglo XVIII. A propósito de algunos trabajos de Francisco Martínez Marina / Origin's Fables and Grammar of Nation in the XVIII Century Spain. About some Works by Francisco Martínez Marina

\subsection{José María IÑURRITEgui Rodríguez}

Constitución increada: Francisco Martínez Marina y la crítica bíblica / Uncreated Constitution. Francisco Martínez Marina and Biblical Criticism

\subsection{David A. Abián Cubillo}

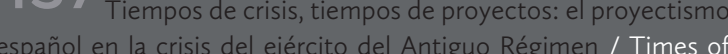
crisis, Times of Projects: The Spanish proyectismo during the Army's Crisis in the Ancient Regime

Taller de historiografía · Historiography Workshop

\section{Ensayos · Essays}

\subsection{ChrISTOPH ROSENMÜLLER}

«Tan peligrosas y feas conspiraciones»: la relación escrita por el embajador austriaco Christoph Migazzi en 1754 sobre la caída del marqués de la Ensenada / «Dangerous and Ugly Conspiracies». The Report of the Austrian Ambassador Christoph Migazzi on the Fall of the Marquis of la Ensenada in 1754

\subsection{Serge Gruzinskı}

Quelle histoire enseigner en 2021 ? / ¿Qué historia enseñar en 2021?

\subsection{Carlos Amate Pizarro}

Las relaciones hispano-chinas en el siglo XVI: síntesis e interpretación a la luz de la reciente historiografía / The Hispanic-chinese Relationship in the XVI Century: Synthesis and Interpretation in the Light of Recent Historiography

\section{Reseñas • Book Review}

521 Bolufer Peruga, Mónica, Arte y artificio de la vida en común. Los modelos de comportamiento y sus tensiones en el Siglo de las Luces, (Julio ArRoyo Vozmediano) 


\section{4 ESPACIO, TIEMPO Y FORMA}

525 Melón, Amando, Alejandro de Humboldt. Vida y obra (Carlos Martínez Shaw)

52 Commentary to Tatiana Seijas' review of The Atlantic World and the Manila Galleons: Circulation, Market, and Consumption of Asian Goods in the Spanish Empire (JosÉ LuIs GASCH TOMAS)

533 Braguier, Laurey, Servantes de dieu. Les beatas de la Couronne de Castille (1450-1600) (Manuela Águeda GARCÍA-GARRIDO)

539 Romeo, María CRuz; SAlomón, María Pilar; TABANERA, Nuria (eds.): Católicos, Reaccionarios y Nacionalistas. Política e identidad nacional en Europa y América Latina Contemporáneas (JAVIER M. Dos SANTOS)

54 Heredia López, Alfonso Jesús, El control de la corrupción en la Monarquía Hispánica. La Casa de la Contratación (1642-1660) (José Manuel Díaz Blanco)

17 Andújar Castillo, Francisco, El Atila de Madrid. La forja de un banquero en la crisis de la monarquía (1685-1715) (Aitor Díaz PAREdes)

551 Serrano Aviles, Javier y Mojarro, Jorge (eds.) Prada GonzALEZ, María (coord. de ilustraciones), En el archipiélago de la Especiería. España y Molucas en los siglos XVI y XVII (İ̃̃ıGo VALPUESTA VILLA)

555 Díaz Ceballos, Jorge, Poder compartido. Repúblicas urbanas, Monarquía y conversación en Castilla del Oro, 1508-1573 (JUAN SEbAstián Gómez GonZÁleZ)

51 Edelmayer, Friedrich, Massimiliano II, Filippo II I'Italia imperiale. II marchesato di Finale, i diritti imperiali e il «camino spagnolo» (RAFAEL VALLADARES)

56 Escribano-PÁEZ, José M., Juan Rena and the Frontiers of Spanish Empire, 1500-1540 (DAvid Martín Marcos)

56 ARNOLD, David, La Era de los Descubrimientos (1400-1600), Madrid, Alianza Editorial, 2021, 184 Pp., ISBN: 978-841362-172-2 (CARlos Amate Pizarro) 